\title{
High-density human mesenchymal stem cell rings with spatiotemporally-controlled morphogen presentation as building blocks for engineering bone diaphyseal tissue
}

\author{
Samuel Herberg1,6, Daniel Varghai ${ }^{1}$, Yuxuan Cheng ${ }^{1}$, Anna D. Dikina ${ }^{1}$, Phuong N. Dang1, Marsha W. \\ Rolle2, Eben Alsberg1,3,4,5凶 \\ 1. Department of Biomedical Engineering, Case Western Reserve University, Cleveland, OH, USA \\ 2. Department of Biomedical Engineering, Worcester Polytechnic Institute, Worcester, MA, USA \\ 3. Department of Orthopaedic Surgery, Case Western Reserve University, Cleveland, OH, USA. \\ 4. National Center for Regenerative Medicine, Division of General Medical Sciences, Case Western Reserve University, Cleveland, OH, USA. \\ 5. School of Dentistry, Kyung Hee University, Seoul, South Korea. \\ 6. Current address: Wake Forest Institute for Regenerative Medicine, Wake Forest School of Medicine, Winston-Salem, NC, USA.
}

$\square$ Corresponding author: Eben Alsberg, Ph.D., Department of Biomedical Engineering, Case Western Reserve University, 10900 Euclid Ave., Cleveland, OH 44106 USA. Email: eben.alsberg@case.edu; Tel: 216-368-6425; Fax: 216-368-4969

(c) Ivyspring International Publisher. This is an open access article distributed under the terms of the Creative Commons Attribution (CC BY-NC) license (https:// creativecommons.org/licenses/by-nc/4.0/). See http://ivyspring.com/terms for full terms and conditions.

Received: 2017.11.09; Accepted: 2017.12.24; Published: 2018.02.11

\begin{abstract}
Emerging biomimetic tissue engineering strategies aim to partially recapitulate fundamental events that transpire during embryonic skeletal development; namely, cellular self-organization and targeted morphogenetic pathway activation. Here, we describe self-assembled, scaffold-free human mesenchymal stem cell (hMSC) rings featuring microparticle-mediated presentation of transforming growth factor- $\beta 1$ (TGF- $\beta 1)$ and bone morphogenetic protein-2 (BMP-2). We tested the hypothesis that spatiotemporally-controlled dual presentation of TGF- $\beta 1$ and BMP-2 is superior in modulating in vitro endochondral ossification of high-density cellular constructs compared to single morphogen delivery. hMSC rings were engineered by seeding cells with microparticles presenting (1) TGF- $\beta 1$, (2) BMP-2, or (3) TGF- $\beta 1+$ BMP-2 in custom agarose wells to facilitate self-assembly within $2 \mathrm{~d}$, followed by horizontal culture on glass tubes for 5 weeks. At day 2, hMSC rings across groups revealed homogenous cellular organization mimetic of early mesenchymal condensation with no evidence of new matrix or mineral deposition. Significant early chondrogenic and osteogenic priming occurred with TGF- $\beta 1+$ BMP-2 presentation compared to single morphogen-loaded groups. By week 5, TGF- $\beta 1$-loaded hMSC rings had undergone chondrogenesis, while presentation of BMP- 2 alone or in conjunction with TGF- $\beta 1$ stimulated chondrogenesis, chondrocyte hypertrophy, and osteogenesis indicative of endochondral ossification. Importantly, tissue mineralization was most compelling with TGF- $\beta 1$ + BMP-2 loading. Lastly, hMSC ring 'building blocks' were shown to efficiently fuse into tubes within $6 \mathrm{~d}$ post self-assembly. The resulting tubular tissue units exhibited structural integrity, highlighting the translational potential of this advanced biomimetic technology for potential early implantation in long bone defects.
\end{abstract}

Key words: growth factors, TGF- $\beta 1$, BMP-2, controlled delivery, microparticles, chondrogenesis, osteogenesis, mold, self-assembly, regenerative medicine

\section{Introduction}

Endochondral ossification in embryonic long bone development is characterized by distinct phases of (1) mesenchymal stem cell (MSC) condensation, (2) MSC differentiation into chondrocytes and subsequent formation of cartilaginous templates, (3) chondrocyte hypertrophy, (4) calcification of the cartilage matrix and chondrocyte apoptosis, and (5) infiltration of an ossification front promoting vascular invasion, bone formation and remodeling [1, 2]. Native bone regeneration involves an intricate 
interplay of cellular machinery and signal transduction, much of which closely parallels aspects of embryonic development. While highly effective for bridging small defects, skeletal fracture healing exhibits limited capacity to regenerate defects exceeding a certain critical size [1, 3]. Situations resulting in the loss of large bone quantities include trauma, tumor resection, arthrodesis, metabolic disease, arthroplasty, or insufficient host regenerative capacity due to co-morbidities or advanced age [4]. These defects can lead to pathological non-unions as a result of damaged vasculature or improper stabilization, with incidence rates of $1-7 \%$ of the more than 5 million femoral fractures occurring annually in the United States [5, 6]. This has motivated a clinical need for effective bone tissue engineering strategies to facilitate successful treatment of large defects. In attempts to more accurately mimic the efficacy of bone development and natural healing in smaller defects, recent approaches for enhancing functional bone regeneration have begun to consider processes critical to ontogenetic development, namely, endochondral ossification [1, 3, 7-9].

Human bone marrow-derived MSCs (hMSCs) are frequently used both clinically and experimentally in bone tissue engineering strategies due to their multipotent capacity to differentiate and mature into chondrogenic and osteogenic cell lineages, and distinct migratory behavior and trophic effects during tissue regeneration [10-12]. A critical limitation of hMSCs, however, involves the gradual loss of proliferative, multipotent and regenerative capacities during standard two-dimensional (2D) monolayer culture [13]. Phenotypic evaluations have shown that high-density biomimetic 3D culture microenvironments support hMSC chondrogenic and osteogenic differentiation and extracellular matrix (ECM) production [14], potentially due to physiologically relevant cell-cell and cell-substrate interactions within a given scaffold-free micro-tissue construct [15]. While synthetic or biologic support matrices are frequently utilized to provide a structure facilitating cellular adhesion, infiltration and implantation, challenges related to scaffold degradation, biocompatibility, cell viability, and perfusion must be addressed before widespread clinical adoption can be achieved [16, 17]. Therefore, avascular cartilage templates derived from scaffold-free, high-density hMSC condensations capable of undergoing endochondral ossification due to growth factor-mediated chondrogenic lineage priming have been developed [18-22]. Previous studies using this approach have generally required lengthy in vitro culture ( $\geq 3$ weeks) and exogenously supplied morphogens (typically transforming growth factor- $\beta$
(TGF- $\beta$ ) members) to instruct cellular constructs to produce cartilaginous templates prior to implantation [18-22]. The lack of precise spatiotemporal control over morphogen presentation, however, in conjunction with the additional time and costs involved, render this approach unfeasible from a clinical perspective.

To that end, we have recently demonstrated robust in situ chondrogenic priming of hMSC aggregates by incorporating biodegradable gelatin microspheres (GM) [23] capable of temporally-controlled, early TGF- $\beta 1$ release $(\sim 60 \%$ by $2 \mathrm{~h}$ [24]), circumventing the need for lengthy supplementation of inductive signals in vitro. The delivery of bone morphogenetic protein-2 (BMP-2), a second TGF- $\beta$ superfamily member, over a more sustained time period $(\sim 60 \%$ by 60 d [24]) was mediated by mineral-coated hydroxyapatite microparticles (MCM). This delivery strategy facilitated both chondrogenesis and osteogenesis in vitro, suggesting potential efficient endochondral priming of the cellular constructs [24]. Importantly, although not directly assessed here, it may be possible to tailor morphogen presentation in both microparticle types by modulating GM crosslinking density, and altering the dissolution kinetics of the MCM mineral coating, respectively [25, 26]. The relatively small size of the spherical high-density aggregates ( 1-1.5 $\mathrm{mm}$ in diameter) may provide scaling challenges for potential implantation in large defects. To address this, we have recently demonstrated the capacity to use this system to form larger self-assembling, scaffold-free hMSC sheets for calvarial defect healing [27] in addition to bilayer constructs for potential osteochondral defect implantation [23, 28]. A modular, scalable, scaffold-free, high-density cell ring assembly system for engineering (1) vascular tissues from human smooth muscle cells [29], (2) cartilaginous tissues from hMSCs that can be fused to form tubular structures [30], or (3) tri-tissue tubular neotracheas comprised of fused cartilaginous and vascular tissue rings with an outer epithelial lining [31] has furthermore been described by our group. To our knowledge, no study to date has demonstrated the ability to engineer ring/tube shaped hMSC condensations that can undergo both robust chondrogenic and osteogenic differentiation without the need for exogenous growth factor supplementation during culture, which would further allow early implantation to facilitate long bone defect healing.

Given the morphological similarities between the cartilaginous, tubular trachea and the diaphysis of long bones, the aim of the present study was to investigate the role of differential in situ morphogen 
priming on chondrogenic and osteogenic differentiation of engineered high-density hMSC rings as 'building blocks' for the engineering of tubular bone tissue. We tested the hypothesis that spatiotemporally-controlled presentation of TGF- $\beta 1$ and BMP-2 within high-density hMSC constructs in a ring geometry induces bone formation, and that this dual delivery is superior in driving in vitro endochondral ossification compared to either TGF- $\beta 1$ or BMP-2 delivery alone.

\section{Materials and Methods}

\section{Experimental design}

\section{First study}

The experimental design featured three groups of tissue rings comprised of hMSCs (1) without gelatin microspheres (GM) or mineral-coated hydroxyapatite microparticles (MCM) (exogenous morphogen presentation in the media: $10 \mathrm{ng} / \mathrm{ml}$ TGF- $\beta 1$ ( $1^{\text {st }} 2$ weeks); $100 \mathrm{ng} / \mathrm{ml}$ BMP-2 (next 3 weeks)), (2) with unloaded GM and MCM (same exogenous growth factor presentation as (1)), or (3) with TGF- $\beta 1$-loaded GM $(0.1 \mu \mathrm{g}$ total TGF- $\beta 1)$ and BMP-2-loaded MCM (0.5 $\mu$ g total BMP-2) (Fig. 1A).

\section{Second study}

The experimental design featured three groups of tissue rings comprised of hMSCs (1) with TGF- $\beta 1$-loaded GM $(0.1 \mu \mathrm{g})$ and unloaded MCM [TGF- $\beta 1$ group], (2) with unloaded GM and BMP-2-loaded MCM $(0.5 \mu \mathrm{g})$ [BMP-2 group], or (3) with TGF- $\beta 1$-loaded GM $(0.1 \mu \mathrm{g})$ and BMP-2-loaded MCM $(0.5 \mu \mathrm{g})$ [TGF- $\beta$ 1+BMP-2 group] (Fig. 1B). Tissue rings were harvested at 5 weeks for biochemical, molecular, and histological analyses.

\section{hMSC isolation and expansion}

hMSCs were isolated from bone marrow aspirate of one healthy male donor (26 years of age), obtained from the posterior iliac crest under a protocol approved by the University Hospitals of Cleveland Institutional Review Board, using a Percoll (Sigma-Aldrich, St. Louis, MO) density gradient, as previously described [32]. Primary hMSCs were expanded for two passages in growth medium containing low-glucose Dulbecco's modified Eagle's medium (DMEM-LG; Sigma-Aldrich), 10\% prescreened fetal bovine serum (FBS; Fisher Scientific, Waltham, MA) and 1\% penicillin/streptomycin (P/S; Fisher Scientific), and cryopreserved until use. Upon thawing, hMSCs were expanded in growth medium supplemented with $10 \mathrm{ng} / \mathrm{ml}$ fibroblast growth factor-2 (FGF-2; R\&D Systems, Minneapolis, MN) and used at passage 4 .

\section{Gelatin microsphere synthesis and TGF- $\beta 1$ loading}

GM were synthesized from $11.1 \%(\mathrm{w} / \mathrm{v})$ gelatin type A (Sigma-Aldrich) using a water-in-oil single emulsion technique, as previously described [23]. GM were crosslinked for $4 \mathrm{~h}$ with $1 \%(\mathrm{w} / \mathrm{v})$ genipin (Wako USA, Richmond, VA), washed 3 times with $\mathrm{diH}_{2} \mathrm{O}$, and lyophilized. Hydrated GM were sized by light microscopy image analysis $(\mathrm{N}=150$; ImageJ software; National Institutes of Health, Bethesda, MD) and the crosslinking density was quantified via ninhydrin assay $(\mathrm{N}=4)$, as reported previously [23, 30]. Lyophilized GM were loaded with a $80 \mu \mathrm{g} / \mathrm{ml}$ solution of recombinant human transforming growth factor- $\beta 1$ (TGF- $\beta 1$; Peprotech, Rocky Hill, NJ; 0.4 $\mu \mathrm{g} / \mathrm{mg}$ ) in phosphate-buffered saline (PBS) for $2 \mathrm{~h}$ at $37^{\circ} \mathrm{C}$. To ensure $100 \%$ growth factor binding, the volume of TGF- $\beta 1$ solution used was less than the microsphere equilibrium swelling volume. Unloaded GM without growth factor were hydrated similarly using only PBS. TGF- $\beta 1$ release from GM with comparable specifications in collagenase-containing PBS has been demonstrated to occur with an initial burst of $\sim 60 \%$ followed by complete release of all loaded growth factor by $10 \mathrm{~d}$ [24].

\section{Hydroxyapatite microparticle mineral coating and BMP-2 loading}

MCM were kindly provided by Dr. William L. Murphy (University of Wisconsin, Madison, WI). Their preparation using low carbonate $(4.2 \mathrm{mM}$ $\mathrm{NaHCO}_{3}$ ) coating buffer and detailed characterization has been reported previously [24]. Lyophilized MCM from the same batch as used in these prior studies were loaded with a $100 \mu \mathrm{g} / \mathrm{ml}$ solution of recombinant human bone morphogenetic protein-2 (BMP-2; Dr. Walter Sebald, Department of Developmental Biology, University of Würzburg, Germany; $6.4 \mu \mathrm{g} / \mathrm{mg}$ ) in PBS for $4 \mathrm{~h}$ at $37^{\circ} \mathrm{C}$. BMP-2-loaded MCM were then centrifuged at $800 \times \mathrm{xg}$ for 2 min and washed 2x with PBS. Unloaded MCM without growth factor were incubated with PBS only and treated similarly. BMP-2 release from this type of MCM in PBS has been shown to occur in a slow and sustained fashion without initial burst and reaching a maximum of $\sim 60 \%$ by $60 \mathrm{~d}$ [24].

\section{Preparation of culture wells}

Custom annular culture well molds $(2 \mathrm{~mm}$ diameter posts; $3.75 \mathrm{~mm}$ wide trough) were 3D printed (Objet260 Connex; Stratasys, Eden Prairie, $\mathrm{MN}$ ). Polydimethylsiloxane (PDMS; Sylgard 184, Dow Corning, Midland, MI) was cured in the printed molds and served as a negative for casting the $2 \%$ w/v agarose (Denville Scientific Inc., Metuchen, NJ) 
culture wells used in this study. Prior to cell seeding, culture wells were incubated over night in serum-free, chemically defined basal medium comprised of high-glucose DMEM (Sigma-Aldrich) with $10 \%$ ITS $^{+}$ Premix (Corning; Fisher Scientific), $1 \mathrm{mM}$ sodium pyruvate (HyClone; Fisher Scientific), $100 \mu \mathrm{M}$ non-essential amino acids (Lonza, Basel, Switzerland), $100 \mathrm{nM}$ dexamethasone (MP Biomedicals, Solon, $\mathrm{OH}$ ), $0.12 \mathrm{mM}$ L-ascorbic acid-2-phosphate (Wako), and 1\% $\mathrm{P} / \mathrm{S}$ (Fisher Scientific) as described previously [30].

\section{Preparation of microparticle-incorporated hMSC rings}

Expanded hMSCs $\left(4.0 \times 10^{5}\right.$ cells/construct; passage 4) were thoroughly mixed with TGF- $\beta 1$-loaded GM $(0.4 \mu \mathrm{g}$ TGF- $\beta 1 / \mathrm{mg}$ GM; $0.3 \mathrm{mg}$

A

\section{First study}
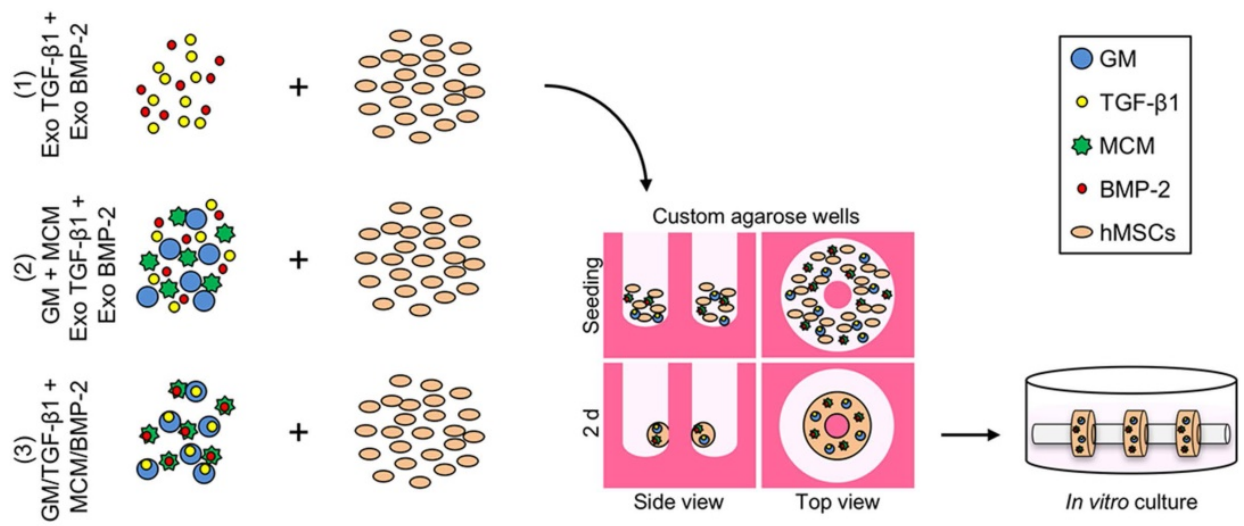

B

Second study
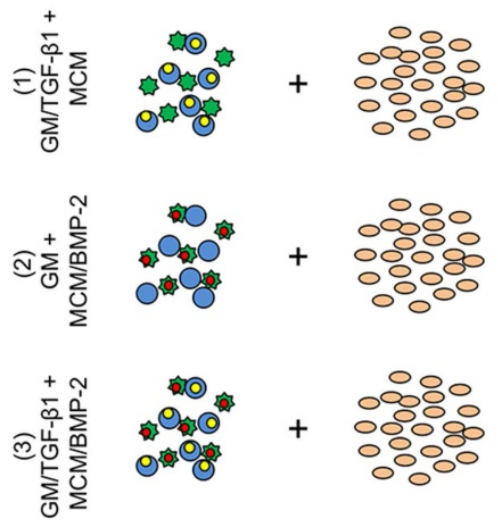
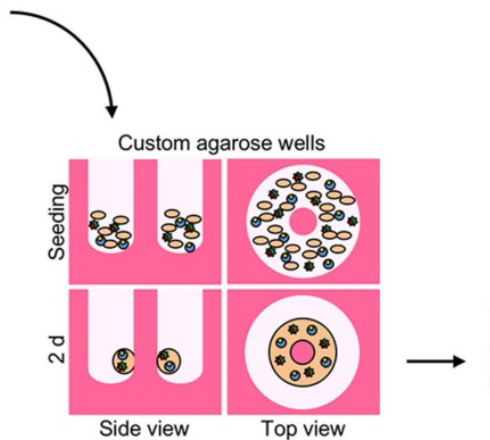

GM/construct) and BMP-2-loaded MCM (6.4 $\mu \mathrm{g}$ BMP-2/mg MCM; $0.08 \mathrm{mg}$ MCM/construct) in basal medium. Fifty microliters of the suspension were seeded in the agarose culture wells as previously described [30] and cellular self-assembly occurred for $2 \mathrm{~d}$ with feeding after $1 \mathrm{~d}$ (Fig. 1). Subsequently, tissue rings were removed from the culture wells and transferred to $2 \mathrm{~mm}$ diameter borosilicate glass tubes (Adams \& Chittenden Scientific Glass, Berkeley, CA). hMSC rings were cultured horizontally and separately on modified custom polycarbonate holders [30] in $60 \mathrm{~mm}$ petri dishes (Corning) containing $10 \mathrm{ml}$ basal medium for 2 weeks, before switching to osteogenic medium for 3 weeks (with exogenous (exo) growth factor supplemented in the media in $1^{\text {st }}$ study as described in the 'Experimental design' and Fig. 1A). This time course was previously shown to facilitate robust endochondral ossification [24]. Osteogenic medium was identical to basal medium but contained $0.17 \mathrm{mM}$ L-ascorbic acid-2-phosphate and $5 \mathrm{mM} \beta$-glycerophosphate [24, 27]. Respective media were replaced every 2 d. All tissue rings described in this report were prepared and cultured in similar fashion; i.e., $1^{\text {st }}$ study: hMSC rings (1) without GM or MCM, (2) with unloaded GM and MCM, or (3) with TGF- $\beta 1$-loaded GM and BMP-2-loaded MCM (Fig. $1 \mathrm{~A}) ; 2^{\text {nd }}$ study: hMSC rings incorporated with (1) TGF- $\beta$ 1-loaded GM and unloaded MCM, (2) unloaded GM and BMP-2-loaded MCM, or (3) TGF- $\beta 1$-loaded GM and BMP-2-loaded MCM (Fig. 1B). Of note, hMSC rings incorporated with unloaded GM and unloaded MCM were prepared and served as controls for qRT-PCR analysis. To assess tissue tube fusion immediately post $2 \mathrm{~d}$ ring self-assembly in the $2^{\text {nd }}$ study, four individual hMSC rings were cultured horizontally in

Finematic of hMSC ring assembly and culture. (A) First study groups: hMSCs (1) without GM MCM plus exogenously (exo) supplemented TGF- $\beta 1$ and BMP-2 in the media, (2) with GM and MCM plus exo TGF- $\beta$ and BMP-2, or (3) with TGF- $\beta 1$-loaded GM and BMP-2-loaded MCM, or (B) second study groups: hMSCs with (1) TGF- $\beta 1$-loaded GM and unloaded MCM, (2) unloaded GM and BMP-2-loaded MCM, or (3) TGF- $\beta 1$-loaded GM and BMP-2-loaded MCM were seeded in custom agarose wells for $2 \mathrm{~d}$ ring self-assembly followed by horizontal culture on glass tubes for 5 weeks. 
contact with each other on glass tubes for 1,3 , and $6 \mathrm{~d}$ in basal medium.

\section{Gross morphological assessment}

hMSC rings from the $1^{\text {st }}$ study $(\mathrm{N}=3)$ were harvested at 5 weeks and gross images taken with a digital SLR camera (Canon, Melville, NY). Ring wall width and height measurements were obtained using calipers (Fowler High Precision, Newton, MA) at the 12,4 , and 8 o'clock positions.

\section{Biochemical analysis}

hMSC rings from the $1^{\text {st }}$ and $2^{\text {nd }}$ study $(\mathrm{N}=3)$ and tubes from the $2^{\text {nd }}$ study $(\mathrm{N}=4)$ were harvested at 5 weeks, homogenized in papain solution $\mathrm{pH} 7.4$ (Sigma-Aldrich) [33], and assayed for alkaline phosphatase activity (ALP assay kit; Sigma-Aldrich), DNA (PicoGreen kit; Invitrogen, Carlsbad, CA) [34], glycosaminoglycan (GAG) (dimethylmethylene blue kit; Sigma-Aldrich) [35], and calcium content (o-cresophthalein complexone assay kit; Pointe Scientific, Canton, MI) as previously described [24].

\section{Quantitative reverse transcription-polymerase chain reaction ( $q R T-P C R)$ analysis}

hMSC rings from the $2^{\text {nd }}$ study $(\mathrm{N}=3)$ were harvested at 2 days and 5 weeks for standard total RNA extraction (TRI Reagent; Sigma-Aldrich), cDNA synthesis (iScript ${ }^{\mathrm{TM}}$ kit; Bio-Rad, Hercules, CA), and qRT-PCR (100 ng cDNA in duplicates; 40 cycles; $60^{\circ} \mathrm{C}$ annealing temperature; Mastercycler (Eppendorf, Hauppauge, NY)) using a SYBR® Premix Ex Taq ${ }^{\mathrm{TM}}$ II kit (Takara Bio Inc., Kusatsu, Shiga, Japan) and custom-designed primers (Table 1; Life Technologies, Grand Island, NY) as described previously [27]. Transcript levels were normalized to GAPDH and mRNA fold-change calculated relative to day 2 control hMSC rings without growth factor using the comparative $\mathrm{C}_{\mathrm{T}}$ method [36].

\section{Fusion analysis}

A binary fusion score was assigned by two independent, blinded observers. After 1, 3, and $6 \mathrm{~d}$, hMSC rings within 4-ring tube constructs $(\mathrm{N}=3$; from the $2^{\text {nd }}$ study) were considered fully fused with their neighboring ring(s) if the tissue tube constructs were resistant to separation by even, manual pulling using high precision dressing forceps with serrated, straight tips (Fisher Scientific).

\section{Histological and immunohistochemical analysis}

hMSC rings from the $1^{\text {st }}$ and rings/tubes from the $2^{\text {nd }}$ study were fixed in $10 \%$ neutral buffered formalin for $24 \mathrm{~h}$ at $4^{\circ} \mathrm{C}$ before switching to $70 \%$ ethanol. Following paraffin processing, $5 \mu \mathrm{m}$ cross sections were cut using a microtome (Leica Microsystems Inc., Buffalo Grove, IL) and stained with hematoxylin \& eosin (H\&E), Safranin-O/ Fast-green (Saf-O), or Alizarin Red S (ARS). For the $2^{\text {nd }}$ study, hMSC tube wall width and height after 6 days of fusion were assessed on H\&E-stained photomicrographs of longitudinal tube sections $(\mathrm{N}=$ 3; width: average of 4 measurements per sample [1 per ring building block; average of both sides]; height: average of 2 measurements per sample [ 1 per side]) using ImageJ software. Immunohistochemistry was performed to examine the presence of collagen ( $\mathrm{Col})$ types I, II, and X in week 5 rings from the $2^{\text {nd }}$ study. All sections were deparaffinized and rehydrated with decreasing concentrations of ethanol, and endogenous peroxidase activity was quenched by submerging slides in $30 \%(\mathrm{v} / \mathrm{v})$ hydrogen peroxide/methanol (1:9) for 10 minutes. For epitope retrieval, sections were digested with pronase $(1 \mathrm{mg} / \mathrm{ml}$; Sigma-Aldrich) in PBS at RT for 15 minutes. Rabbit anti-human Col I (ab138492), rabbit anti-human Col II (ab34712), and rabbit anti-human Col X (ab58632; all from Abcam, Cambridge, MA) were used as primary antibodies. Rabbit IgG (Vector Laboratories) served as negative control. The Histostain-Plus Bulk kit (Invitrogen; Thermo Fisher Scientific, Waltham, MA) with aminoethyl carbazole (Invitrogen) was utilized according to the manufacturer's instructions with Fast-green counterstain. Slides were mounted with glycerol vinyl alcohol (Invitrogen), and light microscopy images were captured using an Olympus BX61VS microscope (Olympus, Center Valley, PA) with a Pike F-505 camera (Allied Vision Technologies, Stadtroda, Germany).

Table 1. Oligonucleotide primer sequences for qRT-PCR.

\begin{tabular}{llll}
\hline Gene & \multicolumn{2}{l}{ Sequence $\left(5^{\prime}\right.$-3 $\left.^{\prime}\right)$} & Accession number \\
\hline SOX9 & Fwd & CACACAGCTCACTCGACCTTG & NM_000346.3 \\
& Rev & TTCGGTTATTTTAGGATCATCTCG & \\
ACAN & Fwd & TGCGGGCAACAGTGCCTATC & NM_001135.3 \\
& Rev & CACGATGCCTTTCACCACGAC & \\
COL2A1 & Fwd & GGAAACTTTGCTGCCAGATG & NM_001844.4 \\
& Rev & TCACCAGGTTCACCAGGATTGC & \\
RUNX2 & Fwd & ACAGAACCACAAGTGCGGTGCAA & NM_001015051.3 \\
& Rev & TGGCTGGTAGTGACCTGCGGA & \\
ALP & Fwd & CCACGTCTTCACATTTGTG & NM_000478.4 \\
& Rev & GCAGTGAAGGGCTTCTTGTC & \\
COL1A1 & Fwd & GATGGATTCCAGTTCGAGTATG & NM_000088.3 \\
& Rev & GTTTGGGTTGCTTGCTGTTTG & \\
GAPDH & Fwd & GGGGCTGGCATTGCCCTCAA & NM_002046.5 \\
& Rev & GGCTGGTGGTCCAGGGGTCT & \\
\hline
\end{tabular}


A

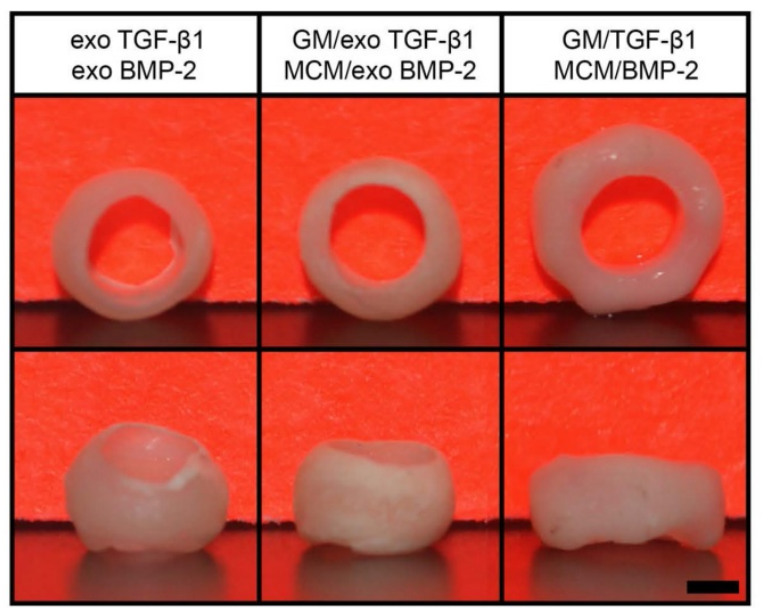

B

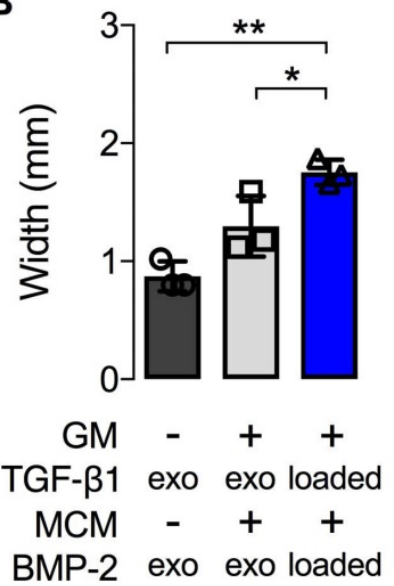

C

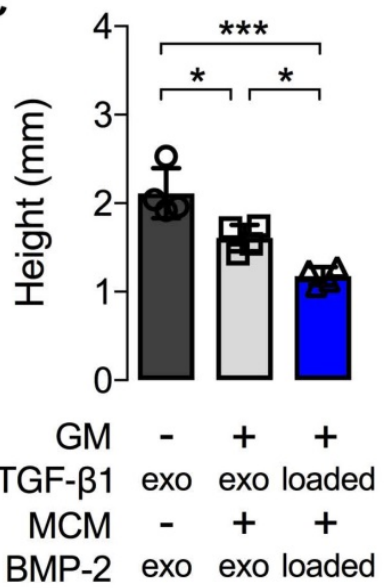

Figure 2. Gross macroscopic characterization of hMSC rings without or with microparticle incorporation and varied mode of morphogen presentation at 5 weeks. (A) Gross macroscopic images of hMSC rings 1) without GM or MCM and exogenous (exo) morphogen supplementation, 2) with unloaded GM and MCM and exo morphogen supplementation, or 3) with TGF- $\beta 1$-loaded GM and BMP-2-loaded MCM. Scale bar = 1 mm. (B,C) hMSC ring wall width and height quantification $\left(\mathrm{N}=3 ;{ }^{*} \mathrm{p}<0.05,{ }^{* *} \mathrm{p}<0.01, * * * \mathrm{p}<0.001\right)$.

\section{Statistical analysis}

Differences in ring gross morphological parameters, biochemical markers, and mRNA fold-changes were assessed by one-way analysis of variance (ANOVA) with Tukey's multiple comparison post hoc test $(\mathrm{p}<0.05)$. Ring fusion was determined by chi-square test for trend in each group $(\mathrm{p}<0.05)$, and corresponding biochemical markers were analyzed by two-way ANOVA with Tukey's post hoc test $(\mathrm{p}<0.05)$. Bar graphs show raw data with mean \pm SD. GraphPad Prism software v6.0 (GraphPad Software, La Jolla, CA) was used for all analyses.

\section{Results}

\section{Gelatin microparticle characterization}

Hydrated GM were light blue in color and predominantly spherical in shape with an average diameter of $52.9 \pm 40.2 \mu \mathrm{m}$ and a crosslinking density of $25.5 \pm 7.0 \%$ (Suppl. Fig. S1).

\section{Microparticle incorporation and mode of morphogen presentation}

An initial 1st study was devised to assess the effects of microparticle incorporation and mode of presenting both TGF- $\beta 1$ and BMP-2, previously shown to robustly enhance high-density aggregate differentiation [24], on hMSC ring osteogenesis. Tissue constructs, without or with embedded microparticles, were formed and cultured with the chondrogenic and osteogenic morphogens sequentially supplemented in the culture media. Alternatively, TGF- $\beta 1$ was loaded in GM for early release and BMP-2 on MCM for more sustained presentation of this growth factor [24], prior to ring self-assembly and culture in media lacking these morphogens. Gross morphological evaluation at 5 weeks showed markedly greater wall width and significantly shorter height of hMSC rings incorporated with microparticles compared to constructs without (Fig. 2A-C). Spatiotemporallycontrolled morphogen presentation from within the condensations significantly increased hMSC ring wall width and significantly decreased ring height relative to specimens devoid of microparticles (Fig. 2A-C). The height of microparticle-embedded hMSC rings supplemented with exogenous morphogens was also significantly shorter than that of rings without microparticles (Fig. 2A-C).

Biochemical analysis at 5 weeks revealed significantly increased DNA, GAG/DNA, and $\mathrm{Ca}^{2+} / \mathrm{DNA}$, as well as absolute GAG, $\mathrm{Ca}^{2+}$, and ALP activity, when TGF- $\beta 1$ and BMP-2 were presented from embedded microparticles compared to hMSC rings alone supplemented with exogenous morphogens (Fig. 3A,B,C,E,F,G). Furthermore, significantly increased GAG/DNA, GAG, and $\mathrm{Ca}^{2+}$ were observed compared to rings with encapsulated microparticles supplemented with exogenous morphogens (Fig. 3B,E,F). No differences in GAG/DNA, $\mathrm{Ca}^{2+} / \mathrm{DNA}, \mathrm{Ca}^{2+}$, and ALP activity were observed between the two groups receiving exogenous growth factors (Fig. 3B,C,D,F,G), while DNA and GAG were significantly higher in rings with microparticles relative to those without (Fig. 3A,E). Comparable levels of ALP activity normalized to DNA were found among all groups (Fig. 3D). Qualitative histological analysis corroborated the gross ring width assessment. Constructs made without microparticles and supplied with exogenous morphogens consisted of predominantly fibrous tissue (i) with no discernible GAG matrix deposition 
(ii), but moderate mineralization (iii) (Fig. 3H,I). hMSC rings encapsulated with microparticles and supplied with exogenous morphogens showed a greater degree of Saf-O staining (ii) relative to constructs devoid of microparticles, with a noticeable bias towards the inside of the rings, yet comparable ARS staining (iii) consistent with the biochemical evaluation (Fig. 3H,I). Microparticle-mediated presentation of TGF- $\beta 1$ and BMP-2 greatly enhanced GAG matrix deposition (ii) with even distribution throughout the tissue. In addition, superior mineralization (iii) compared to the other groups was observed with only a minor bias towards the outside of the rings (Fig. 3H,I).
A

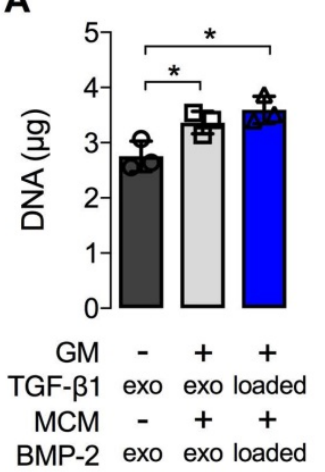

B

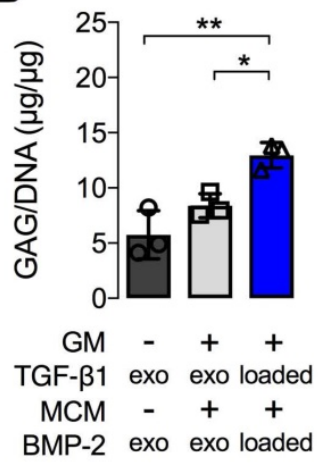

C

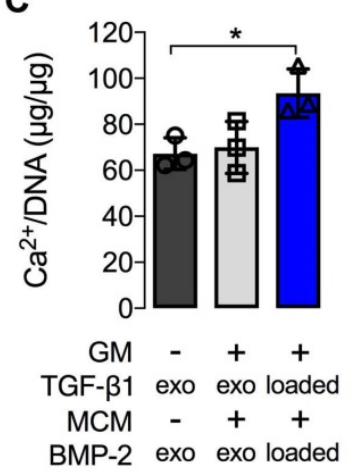

D

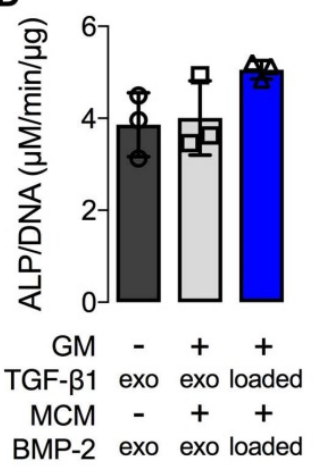

E
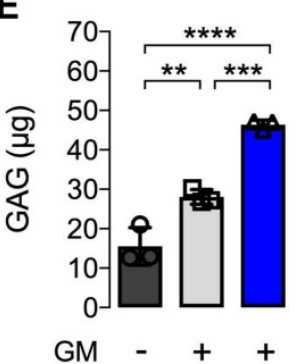

TGF- $\beta 1$ exo exo loaded $\mathrm{MCM}-++$

BMP-2 exo exo loaded
F

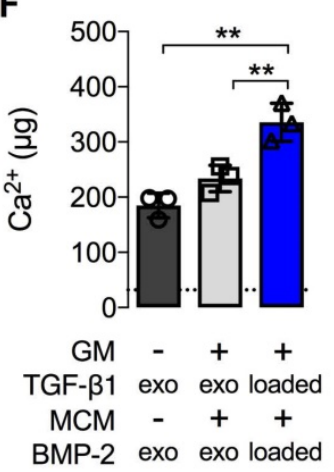

G

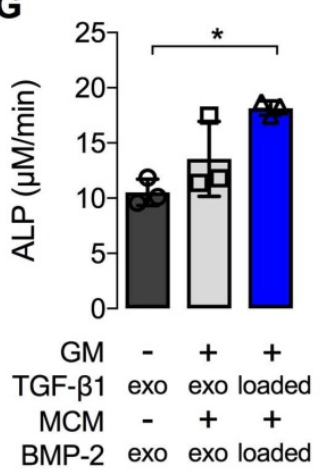

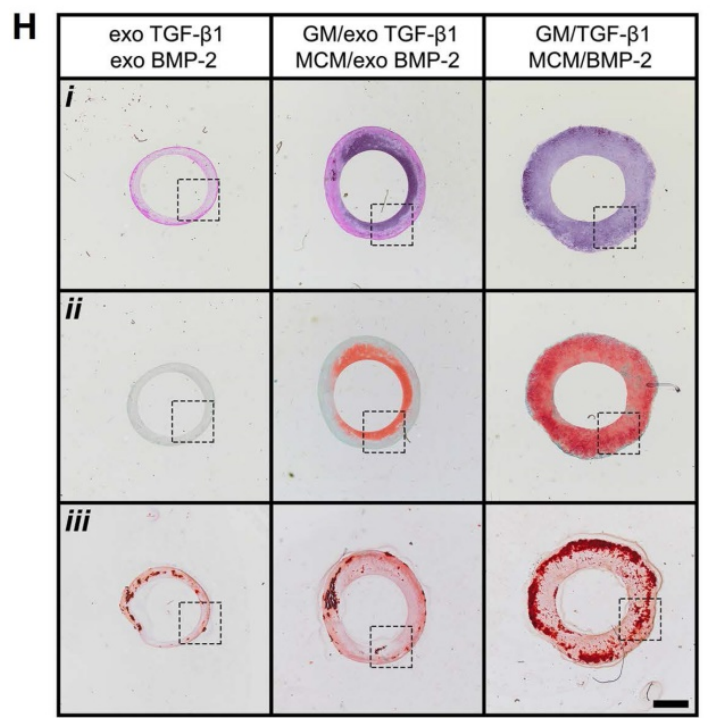

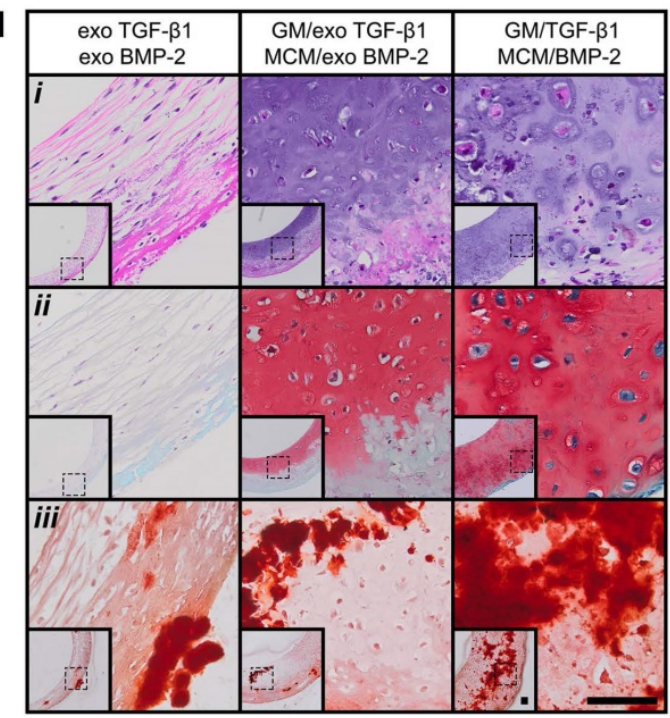

Figure 3. Biochemical profile and histology of hMSC rings without or with microparticle incorporation and varied mode of morphogen presentation at 5 weeks. (A) DNA content, (B) GAG/DNA content, (C) $\mathrm{Ca}^{2+} / \mathrm{DNA}$ content, (D) ALP activity/DNA, (E) GAG content, (F) Ca2+ content; dashed line represents amount of $\mathrm{Ca}^{2+}$ initially contributed by $M C M$ assuming $100 \%$ incorporation into the rings, and $(\mathbf{G}) \mathrm{ALP}$ activity $\left(\mathrm{N}=3 ;{ }^{*} \mathrm{P}<0.05\right.$, $* *{ }^{2}<0.01$, *** $\mathrm{p}<0.001$, ***** $<<0.0001)$. (H,I) Representative photomicrographs of (i) H\&E-, (ii) Saf-O-, and (iii) ARS-stained cross-sections of hMSC rings 1 ) without GM or MCM and exogenous (exo) morphogen supplementation, 2) with unloaded GM and MCM and exo morphogen supplementation, or 3) with TGF- $\beta 1$-loaded GM and BMP-2-loaded MCM. Scale bars = $1 \mathrm{~mm}(\mathbf{( H )}$; dotted squares show region of interest presented in (I) insets) or $100 \mu \mathrm{m}(\mathbf{( I )}$; dotted squares in insets show region of interest in high magnification image). 
A

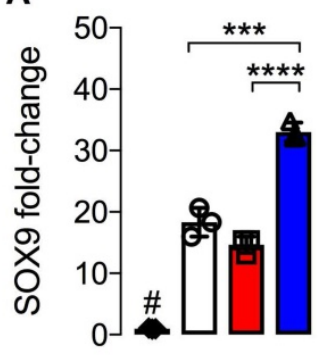

D

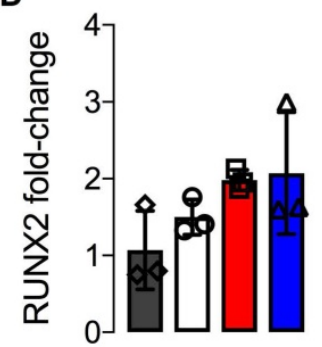

B

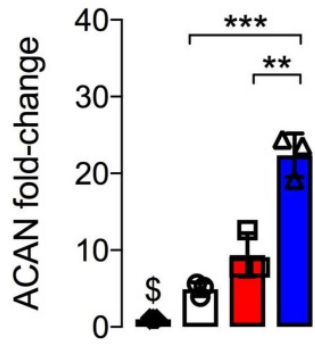

E

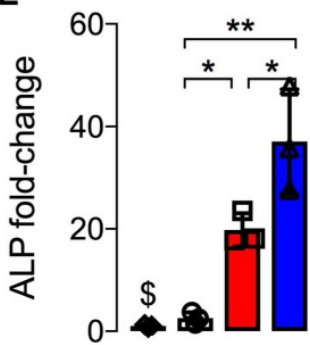

C

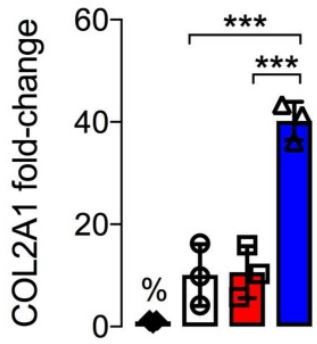

$\mathbf{F}$

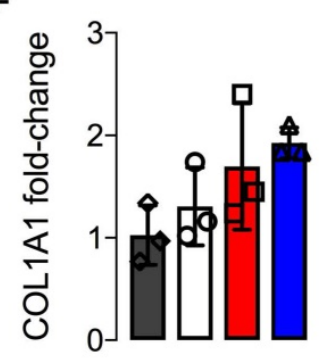

No growth factor TGF- $\beta 1+-+$

control (day 2) BMP-2 -++
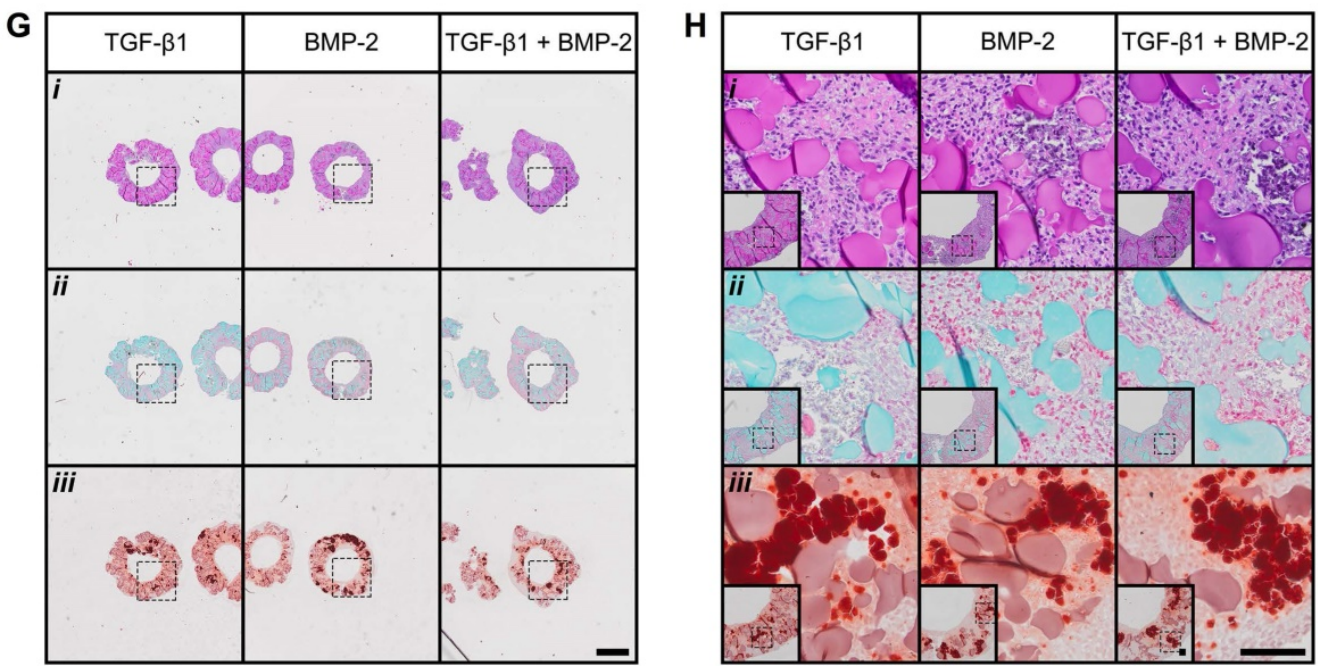

Figure 4. mRNA fold-changes and histology of hMSC rings with varied microparticle-mediated morphogen presentation at 2 days. $m R N A$ fold-changes of chondrogenic markers (A) SOX9, (B) ACAN and (C) COL2A1, and osteogenic markers (D) RUNX2, (E) ALP and (F) COLIAl relative to day 2 control hMSC rings without growth factor loading $\left(N=3 ;{ }^{*}<0.05\right.$, $* * * p<0.001$, $* * * * p<0.0001$; ${ }^{*} p<0.0001$ vs. all other groups, $\$ p<0.01$ vs. BMP-2- and TGF- $\beta 1+$ BMP-2-loaded, \%p<0.0001 vs. TGF- $\beta 1+$ BMP-2-loaded). (G,H) Representative photomicrographs of (i) H\&E-, (ii) Saf-O-, and (iii) ARS-stained cross-sections of hMSC rings with 1) TGF- $\beta 1$-loaded GM and unloaded MCM, 2) unloaded GM and BMP-2-loaded MCM, or 3) TGF- $\beta 1$-loaded GM and BMP-2-loaded MCM. Scale bars = 1 $\mathrm{mm}(\mathbf{( G )}$; dotted squares show region of interest presented in $\mathbf{( H )}$ insets) or $100 \mu \mathrm{m}(\mathbf{( H )}$; dotted squares in insets show region of interest in high magnification image).

\section{Differential microparticle-mediated morphogen presentation}

Owing to the ability to maximize hMSC ring osteogenic differentiation by means of microparticlemediated dual morphogen presentation, the $2^{\text {nd }}$ study investigated the individual contributions of TGF- $\beta 1$ and BMP-2, each delivered from its corresponding microparticle, in comparison to co-delivery. To characterize potential early effects of differential morphogen priming on hMSC rings immediately after self-assembly at day 2 , mRNA fold-changes relative to control hMSC rings without growth factor loading were assessed in conjunction with histological analysis. Presentation of only TGF- $\beta 1$ or BMP-2 resulted in similar mRNA fold-changes of the chondrogenic markers sex determining region Y-box 9 (SOX9), aggrecan (ACAN), and collagen type 2A1 (COL2A1), and the osteogenic markers Runt-related transcription factor 2 (RUNX2) and collagen type 1A1 (COL1A1) (Fig. 4A-D,F) compared to no growth factor loading controls. Significantly greater ALP fold-change was found with BMP-2-only loading compared to TGF- $\beta 1$-only (Fig. 4E). Dual morphogen 
delivery significantly increased mRNA fold-changes of SOX9, ACAN, COL2A1, and ALP compared to the other groups, while RUNX2 and COL1A1 remained unaffected (Fig. 4A-F). Qualitative histology revealed homogeneous cellular organization across tissue ring groups, with relatively evenly distributed GM (i) and no evident extracellular matrix deposition (ii). This was accompanied by equivalent ARS-staining (iii) among all groups that was likely limited to incorporated MCM (Fig. 4G,H).

Upon morphogen priming, the extent of hMSC ring chondrogenic and osteogenic differentiation was assessed after 5 weeks in culture. An overall increase in transcript levels relative to $2 \mathrm{~d}$ was found for all chondrogenic markers. TGF- $\beta 1$ presentation alone resulted in significantly higher mRNA expression levels of SOX9, ACAN, and COL2A1 compared to BMP-2 or dual morphogen delivery, while no differences were observed between the two groups with BMP-2 (Fig. 5A-C). Interestingly, mRNA fold-changes of osteogenic markers RUNX2, ALP and COL1A1 were comparable across all growth factor loaded groups at this time point (Fig. 5D-F), and showed a trend toward slightly increased COL1A1 but decreased ALP mRNA levels compared to $2 \mathrm{~d}$ values of these groups.

Biochemical analysis at 5 weeks revealed comparable DNA levels across groups (Fig. 6A). Significantly higher GAG/DNA was observed with
TGF- $\beta 1$ presentation compared to hMSC rings featuring BMP-2 or dual morphogen delivery (Fig. 6B). By contrast, BMP-2 or TGF- $\beta 1+$ BMP-2 presentation resulted in significantly higher $\mathrm{Ca}^{2+} / \mathrm{DNA}$ and absolute $\mathrm{Ca}^{2+}$ levels relative to TGF- $\beta 1$-loaded constructs (Fig. 6C,F). Moreover, absolute ALP activity was significantly higher with dual morphogen presentation compared to TGF- $\beta 1$ alone (Fig. 6G). Comparable ALP activity normalized to DNA and absolute GAG amounts were found among groups (Fig. 6D,E). Consistent with message- and protein-level analyses, qualitative histological evaluation of tissue rings showed distinct patterns of fate-specification. hMSC constructs were similar in size and cellularity across groups with only few remaining GM (Fig. $6 \mathrm{Hi}, \mathrm{I} i$ ). TGF- $\beta 1$-loaded rings revealed more robust and homogenous Saf-O staining of GAG matrix compared to BMP-2 delivery, while TGF- $\beta 1$ + BMP-2 constructs exhibited nearly comparable Saf-O staining as with TGF- $\beta 1$ alone (Fig. $6 \mathrm{Hii}$,Iii). Across groups, cells with chondrocyte-like morphology were observed in Saf O-stained regions. Little evidence of tissue mineralization was observed with TGF- $\beta 1$ presentation, whereas robust ARS staining of the hMSC rings was seen in the BMP-2 and dual morphogen delivery groups (Fig. 6Hiii,Iiii), with the most extensive staining near the outer perimeter, supporting the quantitative calcium analysis.
A

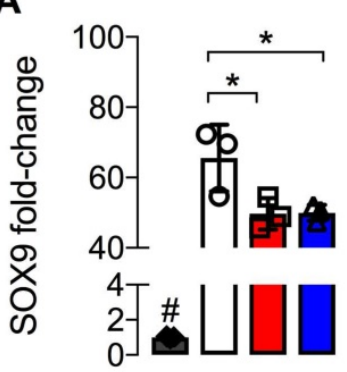

D

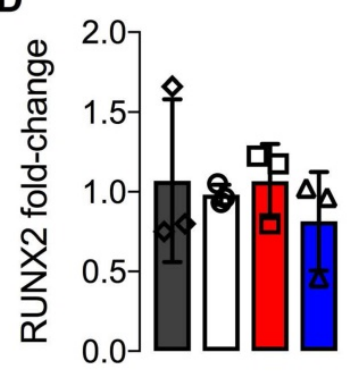

B

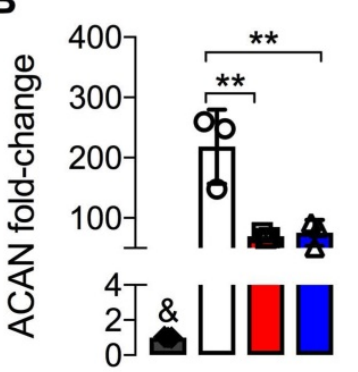

E

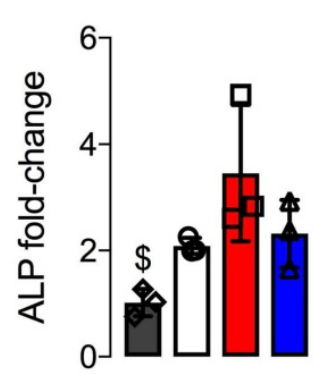

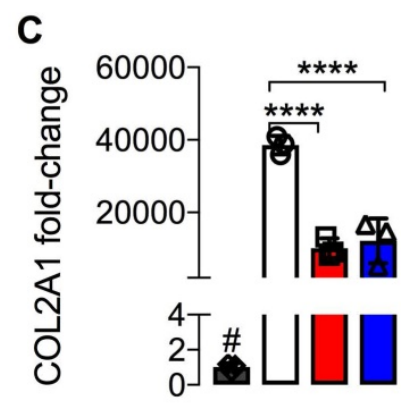

$\mathbf{F}$

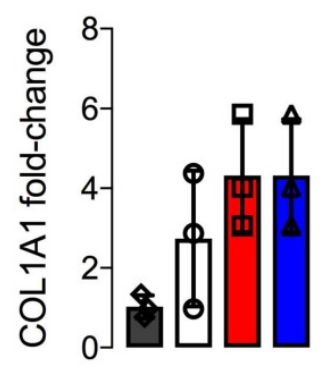

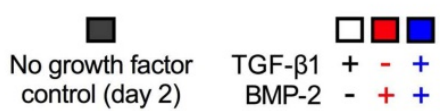

Figure 5. mRNA fold-changes of hMSC rings with varied microparticle-mediated morphogen presentation at 5 weeks. $m R N A$ fold-changes of chondrogenic markers (A) SOX9, (B) ACAN and (C) COL2A1, and osteogenic markers (D) RUNX2, (E) ALP and (F) COL1A1 relative to day 2 control hMSC rings

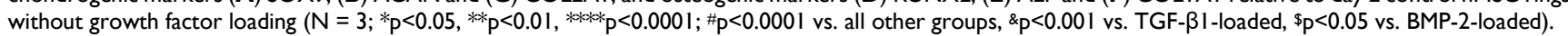


A

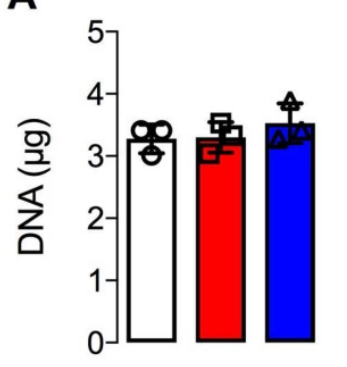

B

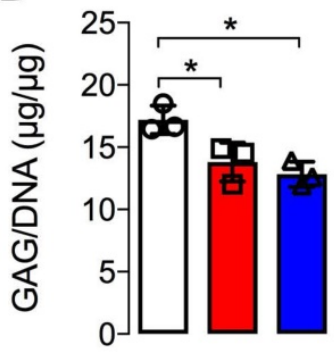

C

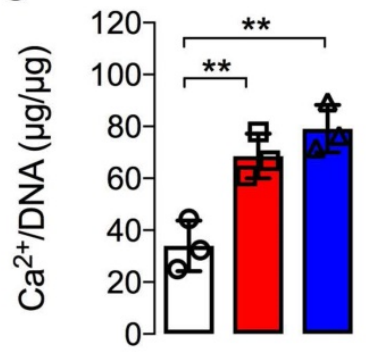

D

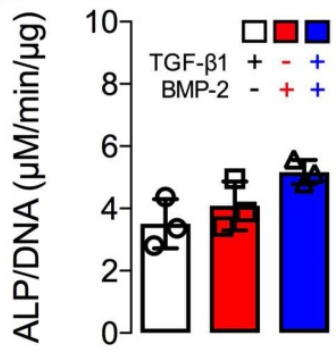

E

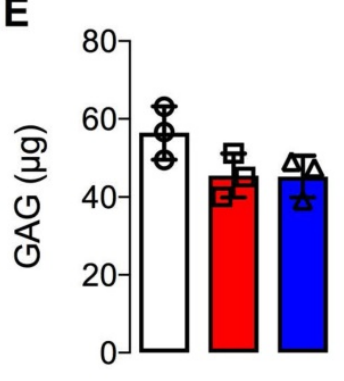

$\mathbf{F}$

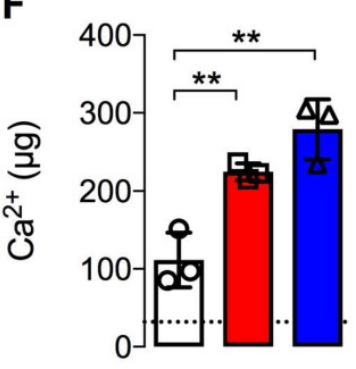

G

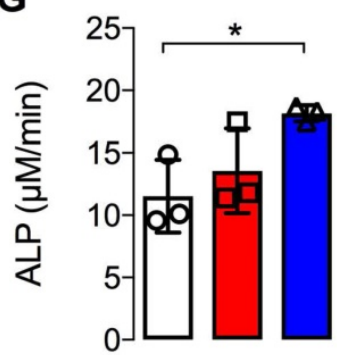

H

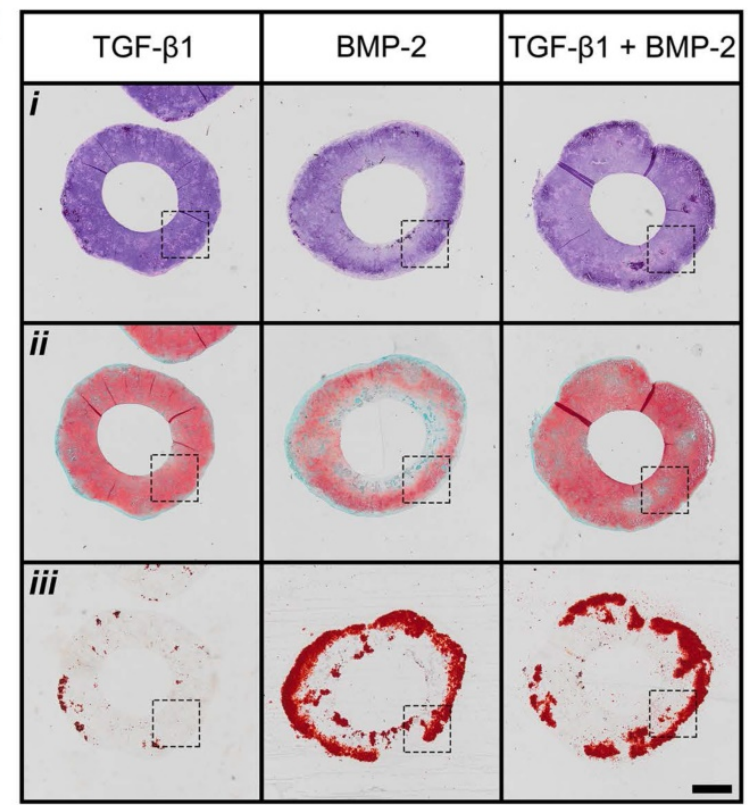

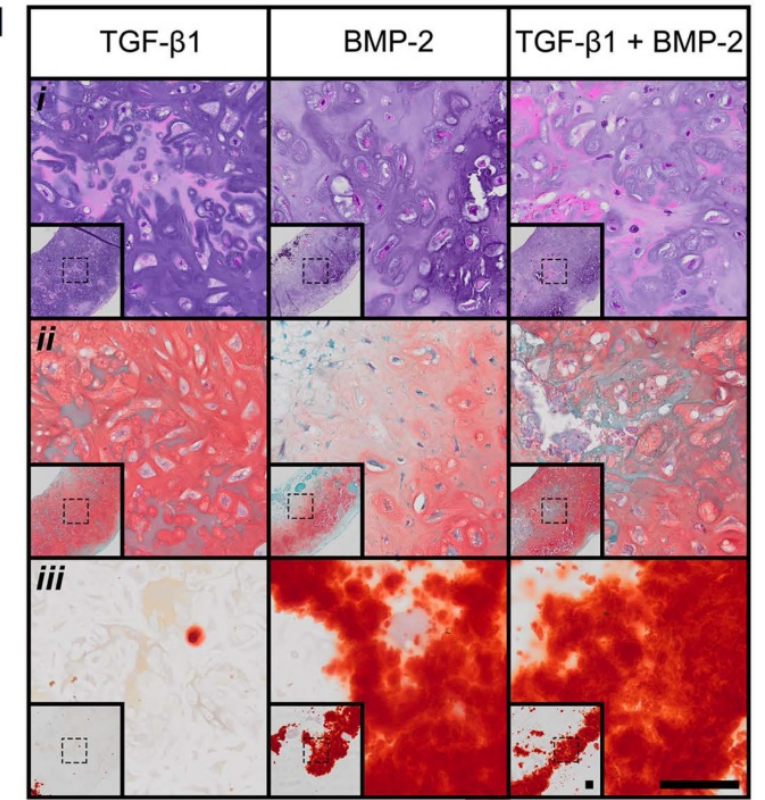

Figure 6. Biochemical profile and histology of hMSC rings with varied microparticle-mediated morphogen presentation at 5 weeks. (A) DNA content, (B) GAG/DNA content, (C) Ca ${ }^{2+} / \mathrm{DNA}$ content, (D) ALP activity/DNA, (E) GAG content, (F) $\mathrm{Ca}^{2+}$ content; dashed line represents amount of Ca ${ }^{2+}$ initially contributed by MCM assuming $100 \%$ incorporation into the rings, and (G) ALP activity $\left(\mathrm{N}=3 ;{ }^{*} \mathrm{p}<0.05\right.$, **p $\left.<0.01\right)$. (H,I) Representative photomicrographs of (i) H\&E-, (ii) Saf-O-, and (iii) ARS-stained cross-sections of hMSC rings with 1) TGF- 31 -loaded GM and unloaded MCM, 2) unloaded GM and BMP-2-loaded MCM, or 3) TGF- $\beta 1$-loaded GM and BMP-2-loaded MCM. Scale bars $=1 \mathrm{~mm}(\mathbf{( H )}$; dotted squares show region of interest presented in (I) insets) or $100 \mu \mathrm{m}((\mathbf{I})$; dotted squares in insets show region of interest in high magnification image).

Immunohistochemistry revealed moderate Col II staining across groups. Relatively comparable levels were observed in TGF- $\beta 1$ - and TGF- $\beta 1+$ BMP-2loaded hMSC rings, while staining in BMP-2-only constructs appeared slightly more pronounced (Fig. 7A,B). Robust overall Col X staining was apparent suggesting the presence of hypertrophic cartilage, with BMP-2-loaded rings again exhibiting the most intense signal throughout (Fig. 7A,B). Interestingly, despite robust ARS staining with BMP-2 or TGF- $\beta 1+$ BMP-2-loading only scarce Col I staining was noted in all rings (Fig. 7A,B).

We recently reported the ability to fuse several chondrogenically-primed hMSC rings to form a tubular cartilage tissue by 3 weeks of in vitro culture [30]. However, the minimum time required to 
establish the initial fusion between 2 day old individual rings was not investigated. In the current study, no fusion occurred in any group after 1 day. By day 3 , only $33 \%$ of tubes were established with TGF- $\beta 1$ or BMP-2 presentation, while $66 \%$ fusion was noted with dual morphogen delivery. By day 6, 66\% fusion occurred in TGF- $\beta 1$-loaded constructs, and $100 \%$ of the 4-ring hMSC tubes were established with BMP-2 or TGF- $\beta 1$ + BMP-2 presentation (Fig. 8A). Biochemical analysis showed comparable GAG/DNA and absolute GAG levels across groups at $3 \mathrm{~d}$ (Fig. 8B,D). By $6 \mathrm{~d}$, significantly higher GAG/DNA and absolute GAG were found in BMP-2 and dual morphogen delivery groups compared to the TGF- $\beta 1$ group (Fig. $8 \mathrm{~B}, \mathrm{D})$. No differences in DNA content were apparent over time and across groups (Fig. 8C). Surprisingly, $\mathrm{Ca}^{2+}$ levels were below the detection limit of the assay. These findings were corroborated by qualitative histological analysis at $6 \mathrm{~d}$ post-fusion. Homogeneous cellular organization and relatively evenly distributed GM were seen within each hMSC ring of the 4-ring tubular constructs in all groups. At the ring junction, some cells within the maturing connective tissue appeared aligned largely parallel to the ring edges (Fig. 8Ei,Fi). Saf-O staining revealed slightly more GAG deposition at this early time point with dual morphogen presentation vs. the other groups (Fig. 8Eii,Fii). Relatively evenly dispersed ARS-staining among all groups was observed localized to incorporated MCM (Fig. 8Eiii,Fiii). Assessment of hMSC tube wall width and height at $6 \mathrm{~d}$ post-fusion revealed no differences between groups (Suppl. Fig. S2), with construct heights not substantially exceeding $(<10 \%)$ the sum of unfused individual ring building block heights at day 1 post-fusion, independent of morphogen loading.

\section{Discussion}

The central aims of this study were (1) to investigate the effects of spatiotemporally-controlled in situ morphogen presentation on chondrogenic and osteogenic differentiation of novel engineered hMSC aggregates, mimetic of early mesenchymal condensation present during bone morphogenesis [2], formed in a ring geometry, and (2) to determine the capacity of these rings to fuse and form tubular structures resembling long bone diaphyses. Biodegradable crosslinked gelatin microspheres (GM) and mineral-coated hydroxyapatite microparticles (MCM), each exhibiting comparable specifications to those reported previously, were utilized in this study for early presentation of TGF- $\beta 1(\sim 60 \%$ by $2 \mathrm{~h})$ and sustained delivery of BMP-2 $(\sim 60 \%$ by $60 \mathrm{~d})$, respectively [24, 27]. Our data showed that microparticle-mediated morphogen presentation was superior biochemically and histologically in directing cell fate specification in the ring-shaped constructs compared to sequential exogenous supplementation with or without incorporated, unloaded microparticles. Investigating the contribution of TGF- $\beta 1$, BMP-2 or their combination, hMSC rings across groups revealed homogenous cellular organization immediately upon completion of self-assembly with no evidence of GAG matrix, and yet positive $\mathrm{Ca}^{2+}$ staining likely from incorporated MCM rather than new mineral deposition; however, significantly increased chondrogenic/early osteogenic mRNA expression was observed with TGF- $\beta 1+$ BMP-2 presentation compared to single morphogenloaded groups. At 5 weeks, TGF- $\beta 1$-loaded hMSC rings had undergone robust chondrogenesis and exhibited chondrocyte hypertrophy yet comparatively limited osteogenesis, while presentation of BMP-2 either alone or in conjunction with TGF- $\beta 1$ stimulated chondrogenesis, chondrocyte hypertrophy, and osteogenesis suggestive of endochondral ossification, with the most prominent tissue mineralization observed using dual morphogen delivery. Lastly, hMSC 'building blocks' were shown to efficiently fuse within $6 \mathrm{~d}$ of placing rings next to each other, resulting in a tubular tissue unit that retained its structural integrity upon manipulation.

Data from our $1^{\text {st }}$ study demonstrated that incorporation of microparticles during hMSC ring self-assembly facilitates bulking during tissue formation and maturation, as evidenced by morphological, biochemical, and histological analyses. In presence of exogenous morphogens sequentially supplemented in the media, tissue rings containing both GM and MCM were characterized by significantly greater GAG matrix and mineral deposition by week 5 of in vitro culture compared to constructs formed without microparticles. However, this mode of bioactive cue presentation is hampered by limited spatial control. Utilizing the incorporated microparticles as delivery platform to spatiotemporally control TGF- $\beta 1$ and BMP-2 bioavailability significantly augmented both chondrogenic and osteogenic differentiation of hMSC rings. Importantly, this controllable and localized growth factor delivery strategy eliminates the need for time- and cost-ineffective repeated supplementation with exogenous morphogens while potentially avoiding issues stemming from diffusion limitations, consistent with our previous studies investigating scaffold-free spherical aggregates $[24,25,37-39]$ or disc-like sheets $[23,27,28,38]$. Therefore, the $2^{\text {nd }}$ study investigated the relative contribution of TGF- $\beta 1$ and BMP-2 presented from GM and MCM, respectively, to direct cell fate specification in comparison to dual delivery. 
Owing to their critical roles in cell proliferation, mesenchymal condensation, fate specification, and matrix synthesis during cartilage and bone morphogenesis [40,41], two members of the TGF- $\beta$ superfamily were selected for microparticle-loading and incorporation within the engineered rings: TGF- $\beta 1$ and BMP-2. Genipin-crosslinked GM permit cell-ECM interactions during 3D hMSC ring self-assembly and provide space for cell migration, proliferation, and new matrix deposition as they are degraded by cell-secreted enzymes. Cell-mediated biodegradation of incorporated microspheres appeared largely completed by week 5 in culture, in agreement with previous studies [23-25, 27]. Importantly, the degradation of the GM is correlated with the release of the ionically-complexed morphogen TGF- $\beta 1$. At the chosen crosslinking density of $25.5 \pm 7.0 \%$, TGF- $\beta 1$ has been shown to be completely released from the GM within $10 \mathrm{~d}$ when incubated in collagenase-containing PBS [24], suggesting early bioavailability within cellular constructs. By the same token, uniform mineral coating of hydroxyapatite microparticles allows for binding of morphogens such as BMP-2 via electrostatic interactions between calcium phosphate mineral surfaces within the nano-structured coating and protein side chains. Using a low carbonate coating buffer, BMP-2 has been reported to be released in a sustained manner reaching approximately $60 \%$ by $60 \mathrm{~d}$ while maintaining bioactivity $[24,39]$. Due to their small size of $3.41 \pm$ $1.04 \mu \mathrm{m}$ [24], incorporated MCM may function predominantly as mineralization nucleation sites during the formation of new bone-like tissue rather than adding bulk to the forming structures given their $\sim 15$-fold smaller average size and $\sim 4$-fold lower amount per hMSC ring compared to GM. Importantly, although not directly evaluated here, the described platform of in situ morphogen presentation to high-density hMSC constructs via biodegradable microparticles provides several opportunities to modulate cellular behavior in a context-dependent manner. Firstly, one could vary microparticle size or weight $\%$ per construct, or morphogen type or loading dose, with or without altering overall cell number. Secondly, it is possible to fine tune release of multiple morphogens from either microparticle by modulating the GM crosslinking density and dissolution kinetics of the MCM mineral coating, respectively.

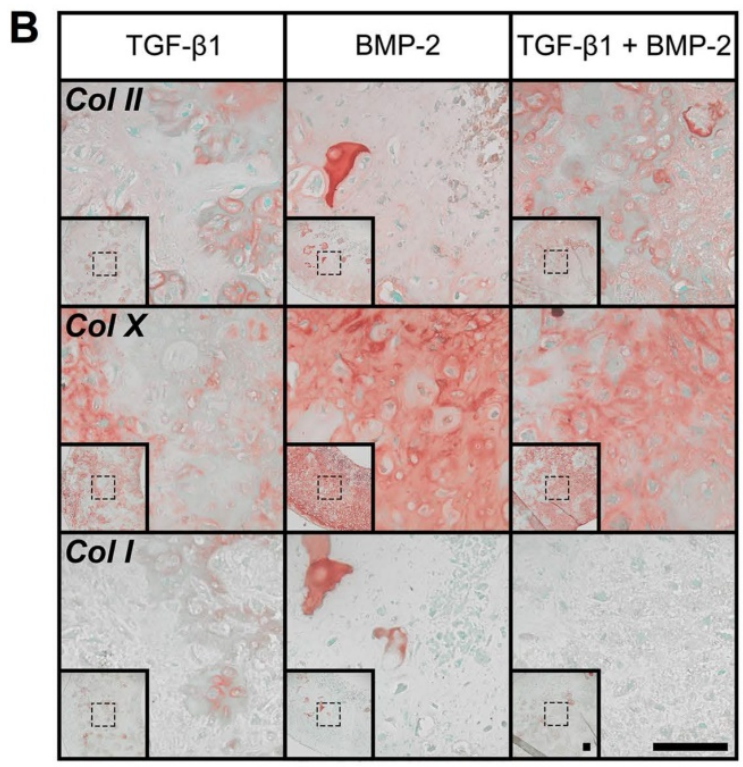

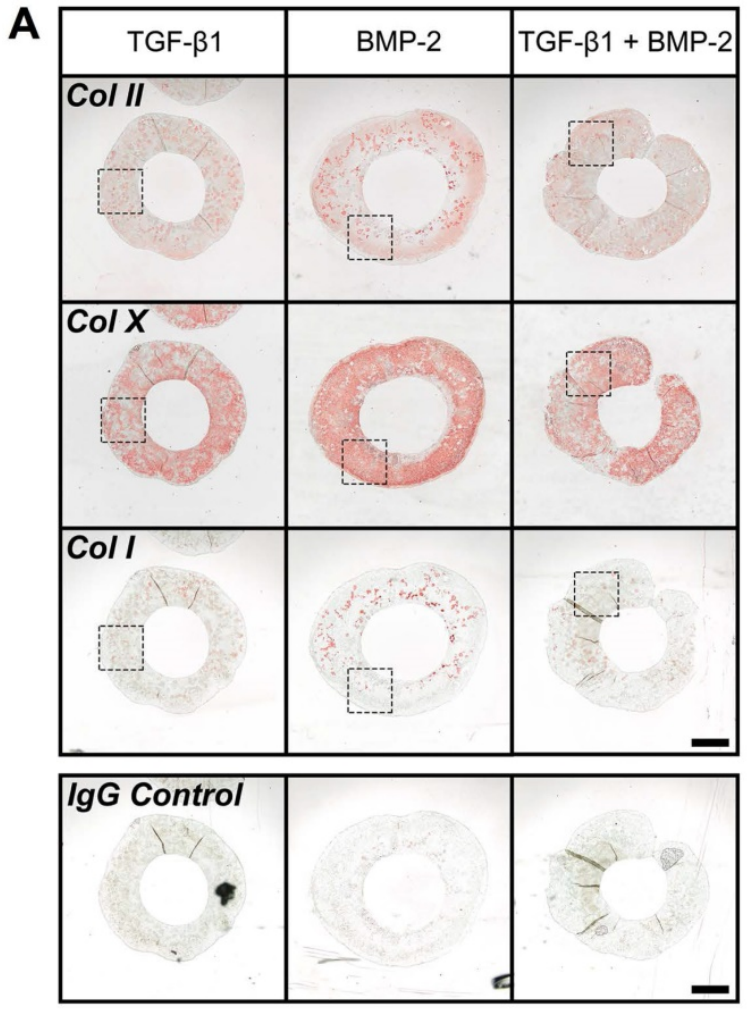

Figure 7. Immunohistochemistry of hMSC rings with varied microparticle-mediated morphogen presentation at 5 weeks. (A,B) Representative photomicrographs of Col II-, Col X-, and Col l-stained cross-sections of hMSC rings (plus representative lgG negative control) with 1) TGF- $\beta 1$-loaded GM and unloaded MCM, 2) unloaded GM and BMP-2-loaded MCM, or 3) TGF- $\beta 1$-loaded GM and BMP-2-loaded MCM. Scale bars $=1 \mathrm{~mm}((\mathbf{A})$; dotted squares show region of interest presented in (B) insets) or $100 \mu \mathrm{m}((\mathbf{B})$; dotted squares in insets show region of interest in high magnification image). 
A

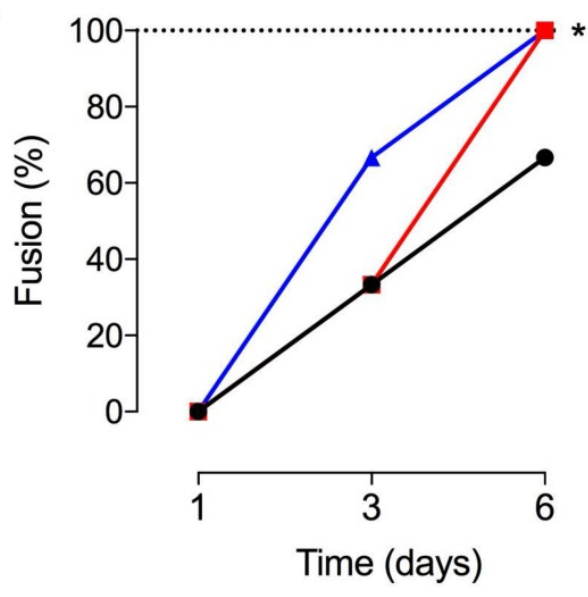

C

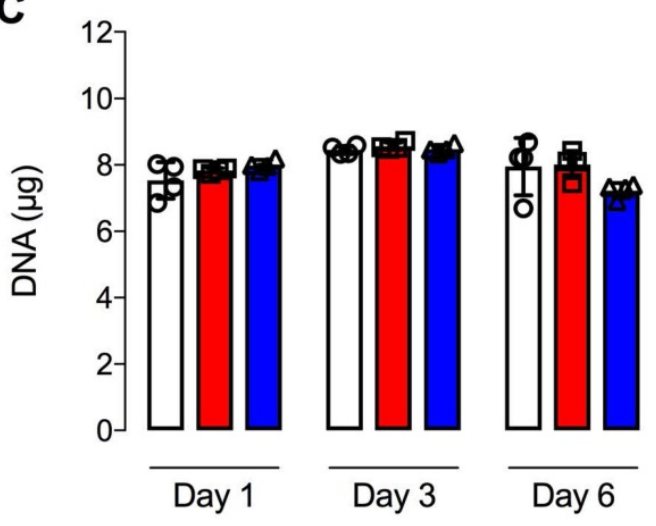

E

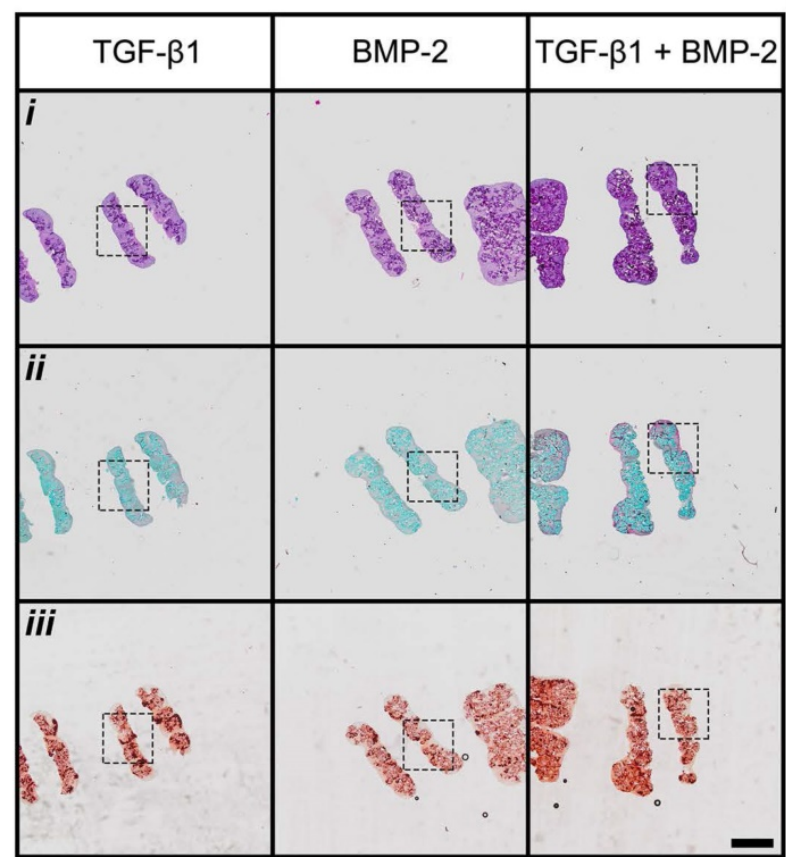

B

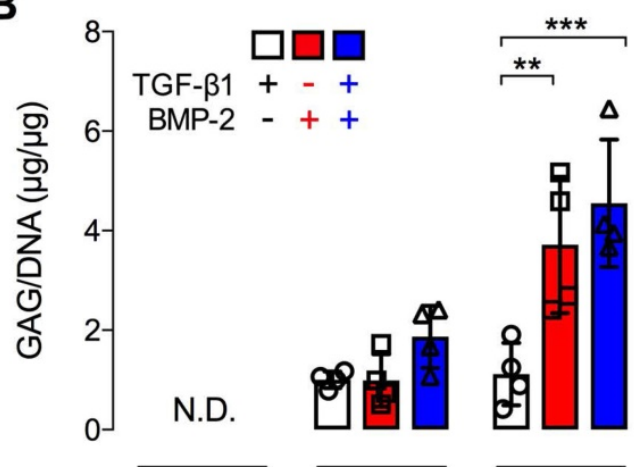

Day $1 \quad$ Day $3 \quad$ Day 6

D

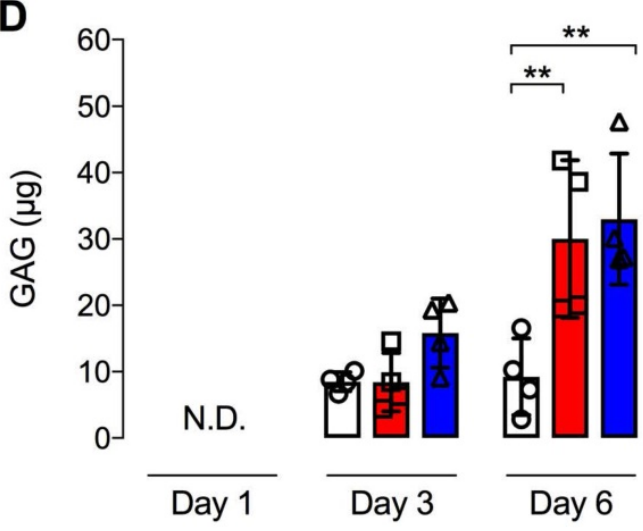

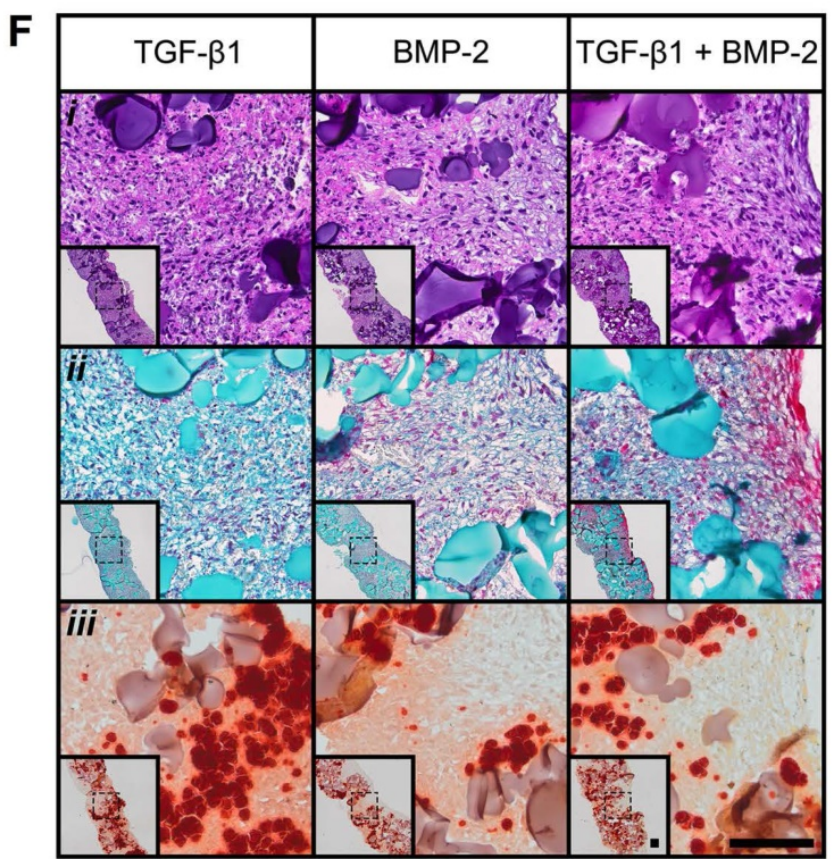

Figure 8: Fusion scoring, biochemical analysis, and histology of 4-ring hMSC tubes with varied microparticle-mediated morphogen presentation. (A) Percentage of $4 \mathrm{hMSC}$ ring samples that longitudinally fused into tubes ( $\left.N=3 ;{ }^{*} \mathrm{p}<0.05\right)$ and (B) GAG/DNA content, (C) GAG content, and (D) DNA content at days 1,3 and 6 on glass tubes $(N=4$; **p $<0.01$, ***p $<0.001)$. (E,F) Representative photomicrographs of (i) H\&E-, (ii) Saf-O-, and (iii) ARS-stained longitudinal-sections of 4-ring hMSC tubes with 1) TGF- $\beta 1$-loaded GM and unloaded MCM, 2) unloaded GM and BMP-2-loaded MCM, or 3) TGF- $\beta 1$-loaded GM and BMP-2-loaded MCM at day 6 on glass tubes. Scale bars $=1 \mathrm{~mm}(\mathbf{E})$; dotted squares show region of interest presented in (F) insets) or $100 \mu \mathrm{m}((\mathbf{F})$; dotted squares in insets show region of interest in high magnification image). 
Unlike traditional bone tissue engineering strategies which direct osteogenic differentiation and new bone formation through intramembranous ossification [42-45], chondrogenic induction by means of effective lineage priming, for example through the use of chondrogenic growth factors such as TGF- $\beta 1$, initiates the formation of a cartilaginous anlage able to progress through endochondral ossification by matrix remodeling and concurrent vascular invasion $[8,9$, 18-22, 46, 47]. Therefore, the latter approach presents an intriguing avenue to potentially overcome challenges such as susceptibility to hypoxic conditions, poor engraftment, and unsatisfactory osteogenic performance of the engineered graft [19]. Assessment of morphogen-mediated lineage priming immediately upon completion of the $2 \mathrm{~d}$ hMSC ring self-assembly process indicated that constructs across groups remained phenotypically undifferentiated at this stage, as evidenced by histology. However, TGF- $\beta 1+$ BMP-2 dual morphogen presentation conferred robust chondrogenic/early osteogenic priming of hMSC rings at the mRNA level compared to single growth factor delivery groups. This suggests that the two TGF- $\beta$ superfamily members may have exerted potentiating effects on early lineage commitment within the high-density cellular constructs downstream of their stringent ligand-receptor specificity [48], exceeding the stimulatory response of the individual morphogens. By week 5, TGF- $\beta 1$-loaded hMSC rings exhibited significantly higher SOX9, ACAN, and COL2A1 mRNA levels compared to BMP-2 or dual morphogen presentation, potentially indicating a more delayed and/or sustained chondrogenic induction. SOX9 is a critical transcription factor regulating sex determination, chondrocyte homeostasis, and several developmental processes [49]. Importantly, SOX9 is expressed in all chondro-progenitor cells during cartilage development, and it plays fundamental roles in the formation of cartilage blastema in limb mesenchyme, chondrocyte proliferation and differentiation in the fetal growth plate, and the regulation of ACAN and COL2A1, two major structural components of cartilage ECM [50, 51]. Biochemical GAG analysis, positive Saf-O and Col II staining and qualitative cell morphologic evaluation of TGF- $\beta$ 1-loaded hMSC rings at 5 weeks, in conjunction with limited calcium production and ARS staining, revealed that this growth factor alone had a predominantly chondroinductive effect in this system. BMP-2 is a potent osteoinductive morphogen used clinically for the treatment of delayed fracture union and spinal fusion [52]. Particularly in combination with TGF- $\beta 1 / 3$, BMP-2 has also been shown to enhance chondrogenic lineage specification in high-density hMSC constructs [53-55]. Our data showed that BMP-2 presented from MCM either alone or in combination with TGF- $\beta 1$-loaded GM stimulated the accumulation of GAG-rich ECM with significantly more deposited mineral compared to TGF- $\beta 1$-loaded hMSC rings. Taken together, this indicates that BMP-2 and dual morphogen presentation potently stimulated both chondrogenic and osteogenic differentiation while immunohistochemistry further revealed abundant $\mathrm{Col} \mathrm{X}$-expressing hypertrophic chondrocytes, suggesting the presence of calcified hypertrophic cartilage - a hallmark of endochondral ossification.

The current work builds on our previous reports using scaffold-free hMSC aggregates and sheets [24, 27], demonstrating the capacity for spatiotemporal control of cell differentiation by means of microparticle-mediated growth factor presentation with unique, defined construct geometries. The ability to precisely control morphogen bioavailability and thereby instruct cellular behavior in situ is especially intriguing as relatively low doses $(\sim 0.1-0.5 \mu \mathrm{g})$ of expensive morphogens (often $>\$ 5000$ per mg [56]) can be used for initial microparticle loading. Furthermore, microparticle-mediated morphogen presentation eliminates the need for cost-ineffective repeated growth factor supplementation during lengthy in vitro culture, and may allow for earlier implantation of cellular constructs for healing of bone defects. To that end, we showed that multiple hMSC ring 'building blocks' can be stacked and fused efficiently within only $6 \mathrm{~d}$ post-ring assembly on glass tubes to form tissue tubes similar in geometry to the diaphysis of long bones. The tubular tissue unit formed in this process was demonstrated to retain its structural integrity upon manipulation, highlighting the translational potential of this technology for advanced biomimetic bone tissue engineering applications. Ongoing studies are focused on investigating the potential of these hMSC tubes to stimulate ectopic and orthotopic bone formation.

\section{Conclusions}

This study describes a biomimetic human stem cell-based tissue engineering approach that partially replicates mesenchymal condensation and activation of morphogenetic pathways in specific spatiotemporal arrangements. The strategy employed permits delivery of potent chondro- and osteoinductive growth factors from encapsulated microparticles for in situ control of cell fate specification within condensations of defined geometry, which advances the clinical utility of high-cell density constructs for bone regeneration. The modular nature of the scaffold-free hMSC ring 
system offers the possibility to form hMSC tubes that resemble the principle geometry of the long bone diaphysis, therefore endowing them with the capacity to serve as 'building blocks' for bone tissue engineering via endochondral ossification.

\section{Abbreviations}

ACAN: aggrecan; ARS: Alizarin Red S; ALP: alkaline phosphatase; BMP-2: bone morphogenetic protein-2; $\mathrm{Ca}^{2+}$ : Calcium; COL1A1/2A1: collagen type 1/2 A1; DNA: deoxyribonucleic acid; Exo: exogenous; GAG: glycosaminoglycan; GAPDH: glyceraldehyde3-phosphate dehydrogenase; GM: gelatin microspheres; H\&E: Hematoxylin \& eosin; hMSCs: human mesenchymal stromal/stem cells; MCM: mineralcoated hydroxyapatite microparticles; N.D.: not detectable; RUNX2: Runt-related transcription factor 2; Saf-O: Safranin-O/Fast green; SOX9: sex determining region Y-box 9; TGF- $\beta 1$ : transforming growth factor- $\beta 1$.

\section{Supplementary Material}

Supplementary figures.

http://www.ntno.org/v02p0128s1.pdf

\section{Acknowledgments}

The authors thank Dr. Xiaohua Yu and Dr. William L. Murphy (University of Wisconsin, Madison, WI) for providing the mineral-coated hydroxyapatite microparticles. We appreciate the technical support of Amad Awadallah, Case Western Reserve University Histology Core Facility. We gratefully acknowledge funding from the National Institutes of Health's National Institute of Dental and Craniofacial Research under award number F32DE024712 (S.H.), the National Institute of Arthritis and Musculoskeletal and Skin Diseases under award number R01AR063194 (E.A.) and National Institute of Biomedical Imaging and Bioengineering R01EB023907 (E.A.). The contents of this publication are solely the responsibility of the authors and do not necessarily represent the official views of the National Institutes of Health.

\section{Competing Interests}

The authors have declared that no competing interest exists.

\section{References}

1. Thompson EM, Matsiko A, Farrell E, Kelly DJ, O'Brien FJ. Recapitulating endochondral ossification: a promising route to in vivo bone regeneration. J Tissue Eng Regen Med. 2015; 9: 889-902.

2. Lefebvre V, Bhattaram P. Vertebrate skeletogenesis. Curr Top Dev Biol. 2010; 90: 291-317.

3. Dennis SC, Berkland CJ, Bonewald LF, Detamore MS. Endochondral ossification for enhancing bone regeneration: converging native extracellular matrix biomaterials and developmental engineering in vivo. Tissue Eng Part B Rev. 2015; 21: 247-66.
4. Kraus KH, Kirker-Head C. Mesenchymal stem cells and bone regeneration. Vet Surg. 2006; 35: 232-42.

5. Schappert SM, Rechtsteiner EA. Ambulatory medical care utilization estimates for 2007. Vital Health Stat 13. 2011: 1-38.

6. Nandra R, Grover L, Porter K. Fracture non-union epidemiology and treatment. Trauma. 2016; 18: 3-11.

7. Oliveira SM, Amaral IF, Barbosa MA, Teixeira CC. Engineering endochondral bone: in vitro studies. Tissue Eng Part A. 2009; 15: 625-34.

8. Simmons CA, Alsberg E, Hsiong S, Kim WJ, Mooney DJ. Dual growth factor delivery and controlled scaffold degradation enhance in vivo bone formation by transplanted bone marrow stromal cells. Bone. 2004; 35: 562-9.

9. Alsberg E, Anderson KW, Albeiruti A, Rowley JA, Mooney DJ. Engineering growing tissues. Proc Natl Acad Sci U S A. 2002; 99: 12025-30.

10. Bruder SP, Fink DJ, Caplan AI. Mesenchymal stem cells in bone development, bone repair, and skeletal regeneration therapy. J Cell Biochem. 1994; 56: 283-94.

11. Caplan AI. Why are MSCs therapeutic? New data: new insight. J Pathol. 2009; 217: 318-24.

12. Caplan AI, Dennis JE. Mesenchymal stem cells as trophic mediators. J Cell Biochem. 2006; 98: 1076-84.

13. Mueller-Klieser W. Three-dimensional cell cultures: from molecular mechanisms to clinical applications. Am J Physiol. 1997; 273: C1109-23.

14. Muraglia A, Corsi A, Riminucci M, Mastrogiacomo M, Cancedda R, Bianco P, et al. Formation of a chondro-osseous rudiment in micromass cultures of human bone-marrow stromal cells. J Cell Sci. 2003; 116: 2949-55.

15. Langenbach F, Naujoks C, Smeets R, Berr K, Depprich R, Kubler N, et al. Scaffold-free microtissues: differences from monolayer cultures and their potential in bone tissue engineering. Clin Oral Investig. 2013; 17: 9-17.

16. Lyons FG, Al-Munajjed AA, Kieran SM, Toner ME, Murphy CM, Duffy GP, et al. The healing of bony defects by cell-free collagen-based scaffolds compared to stem cell-seeded tissue engineered constructs. Biomaterials. 2010; 31: 9232-43.

17. Badylak SF, Gilbert TW. Immune response to biologic scaffold materials. Semin Immunol. 2008; 20: 109-16.

18. Pelttari K, Winter A, Steck E, Goetzke K, Hennig T, Ochs BG, et al. Premature induction of hypertrophy during in vitro chondrogenesis of human mesenchymal stem cells correlates with calcification and vascular invasion after ectopic transplantation in SCID mice. Arthritis Rheum. 2006; 54: 3254-66.

19. Scotti C, Tonnarelli B, Papadimitropoulos A, Scherberich A, Schaeren S, Schauerte A, et al. Recapitulation of endochondral bone formation using human adult mesenchymal stem cells as a paradigm for developmental engineering. Proc Natl Acad Sci U S A. 2010; 107: 7251-6.

20. Farrell E, Both SK, Odorfer KI, Koevoet W, Kops N, O'Brien FJ, et al. In-vivo generation of bone via endochondral ossification by in-vitro chondrogenic priming of adult human and rat mesenchymal stem cells. BMC Musculoskelet Disord. 2011; 12: 31.

21. Bahney CS, Hu DP, Taylor AJ, Ferro F, Britz HM, Hallgrimsson B, et al. Stem cell-derived endochondral cartilage stimulates bone healing by tissue transformation. J Bone Miner Res. 2014; 29: 1269-82

22. Freeman FE, Allen AB, Stevens HY, Guldberg RE, McNamara LM. Effects of in vitro endochondral priming and pre-vascularisation of human MSC cellular aggregates in vivo. Stem Cell Res Ther. 2015; 6: 218

23. Solorio LD, Vieregge EL, Dhami CD, Dang PN, Alsberg E. Engineered cartilage via self-assembled hMSC sheets with incorporated biodegradable gelatin microspheres releasing transforming growth factor-beta1. J Control Release. 2012; 158: 224-32.

24. Dang PN, Dwivedi N, Phillips LM, Yu X, Herberg S, Bowerman C, et al. Controlled Dual Growth Factor Delivery From Microparticles Incorporated Within Human Bone Marrow-Derived Mesenchymal Stem Cell Aggregates for Enhanced Bone Tissue Engineering via Endochondral Ossification. Stem Cells Transl Med. 2016; 5: 206-17.

25. Solorio LD, Dhami CD, Dang PN, Vieregge EL, Alsberg E. Spatiotemporal regulation of chondrogenic differentiation with controlled delivery of transforming growth factor-beta1 from gelatin microspheres in mesenchymal stem cell aggregates. Stem Cells Transl Med. 2012; 1: 632-9.

26. Yu X, Khalil A, Dang PN, Alsberg E, Murphy WL. Multilayered Inorganic Microparticles for Tunable Dual Growth Factor Delivery. Adv Funct Mater. 2014; 24: 3082-93.

27. Dang PN, Herberg S, Varghai D, Riazi H, Varghai D, McMillan A, et al. Endochondral Ossification in Critical-Sized Bone Defects via Readily Implantable Scaffold-Free Stem Cell Constructs. Stem Cells Transl Med. 2017; 6: 1644-59.

28. Solorio LD, Phillips LM, McMillan A, Cheng CW, Dang PN, Samorezov JE, et al. Spatially Organized Differentiation of Mesenchymal Stem Cells within Biphasic Microparticle-Incorporated High Cell Density Osteochondral Tissues. Adv Healthc Mater. 2015.

29. Strobel HA, Dikina AD, Levi K, Solorio LD, Alsberg E, Rolle MW. Cellular Self-Assembly with Microsphere Incorporation for Growth Factor Delivery Within Engineered Vascular Tissue Rings. Tissue Eng Part A. 2017; 23: 143-55.

30. Dikina AD, Strobel HA, Lai BP, Rolle MW, Alsberg E. Engineered cartilaginous tubes for tracheal tissue replacement via self-assembly and fusion of human mesenchymal stem cell constructs. Biomaterials. 2015; 52: $452-62$. 
31. Dikina AD, Alt DS, Herberg S, McMillan A, Strobel HA, Zheng Z, et al. A Modular Strategy to Engineer Complex Tissues and Organs. Advanced Science. 2017; In press.

32. Haynesworth SE, Goshima J, Goldberg VM, Caplan AI. Characterization of cells with osteogenic potential from human marrow. Bone. 1992; 13: 81-8.

33. Ponticiello MS, Schinagl RM, Kadiyala S, Barry FP. Gelatin-based resorbable sponge as a carrier matrix for human mesenchymal stem cells in cartilage regeneration therapy. J Biomed Mater Res. 2000; 52: 246-55.

34. McGowan KB, Kurtis MS, Lottman LM, Watson D, Sah RL. Biochemical quantification of DNA in human articular and septal cartilage using PicoGreen and Hoechst 33258. Osteoarthritis Cartilage. 2002; 10: 580-7.

35. Farndale RW, Buttle DJ, Barrett AJ. Improved Quantitation and Discrimination of Sulfated Glycosaminoglycans by Use of Dimethylmethylene Blue. Biochim Biophys Acta. 1986; 883: 173-7.

36. Schmittgen TD, Livak KJ. Analyzing real-time PCR data by the comparative C(T) method. Nat Protoc. 2008; 3: 1101-8.

37. Solorio LD, Fu AS, Hernandez-Irizarry $\mathrm{R}$, Alsberg E. Chondrogenic differentiation of human mesenchymal stem cell aggregates via controlled release of TGF-beta1 from incorporated polymer microspheres. J Biomed Mater Res A. 2010; 92: 1139-44.

38. Dang PN, Solorio LD, Alsberg E. Driving cartilage formation in high-density human adipose-derived stem cell aggregate and sheet constructs without exogenous growth factor delivery. Tissue Eng Part A. 2014; 20: 3163-75.

39. Dang PN, Dwivedi N, Yu X, Phillips LM, Bowerman C, Murphy WL, et al. Guiding chondrogenesis and osteogenesis with mineral-coated hydroxyapatite and BMP-2 incorporated within high-density hMSC aggregates for bone regeneration. ACS Biomater Sci Eng. 2016; 2: 30-42.

40. Shi Y, Massague J. Mechanisms of TGF-beta signaling from cell membrane to the nucleus. Cell. 2003; 113: 685-700.

41. Reddi AH. Bone morphogenetic proteins and skeletal development: the kidney-bone connection. Pediatr Nephrol. 2000; 14: 598-601.

42. Meijer GJ, de Bruijn JD, Koole R, van Blitterswijk CA. Cell-based bone tissue engineering. PLoS Med. 2007; 4: e9.

43. Dimitriou R, Jones E, McGonagle D, Giannoudis PV. Bone regeneration: current concepts and future directions. BMC Med. 2011; 9: 66.

44. Watanabe Y, Harada N, Sato K, Abe S, Yamanaka K, Matushita T. Stem cell therapy: is there a future for reconstruction of large bone defects? Injury. 2016; 47 Suppl 1: S47-51.

45. Farrell E, van der Jagt OP, Koevoet W, Kops N, van Manen CJ, Hellingman $\mathrm{CA}$, et al. Chondrogenic priming of human bone marrow stromal cells: a better route to bone repair? Tissue Eng Part C Methods. 2009; 15: 285-95.

46. Sheehy EJ, Vinardell T, Buckley CT, Kelly DJ. Engineering osteochondral constructs through spatial regulation of endochondral ossification. Acta Biomater. 2013; 9: 5484-92.

47. Yang W, Both SK, van Osch GJ, Wang Y, Jansen JA, Yang F. Effects of in vitro chondrogenic priming time of bone-marrow-derived mesenchymal stromal cells on in vivo endochondral bone formation. Acta Biomater. 2015; 13: 254-65.

48. Nickel J, Dreyer MK, Kirsch T, Sebald W. The crystal structure of the BMP-2:BMPR-IA complex and the generation of BMP-2 antagonists. J Bone Joint Surg Am. 2001; 83A(Suppl 1): S7-14.

49. Lefebvre V, Dumitriu B, Penzo-Mendez A, Han Y, Pallavi B. Control of cell fate and differentiation by Sry-related high-mobility-group box (Sox) transcription factors. Int J Biochem Cell Biol. 2007; 39: 2195-214.

50. de Crombrugghe B, Lefebvre V, Nakashima K. Regulatory mechanisms in the pathways of cartilage and bone formation. Curr Opin Cell Biol. 2001; 13: 721-7.

51. Lefebvre V, Smits P. Transcriptional control of chondrocyte fate and differentiation. Birth Defects Res C Embryo Today. 2005; 75: 200-12.

52. Govender S, Csimma C, Genant HK, Valentin-Opran A, Amit $Y$, Arbel R, et al. Recombinant human bone morphogenetic protein-2 for treatment of open tibial fractures: a prospective, controlled, randomized study of four hundred and fifty patients. J Bone Joint Surg Am. 2002; 84A: 2123-34.

53. Schmitt B, Ringe J, Haupl T, Notter M, Manz R, Burmester GR, et al. BMP2 initiates chondrogenic lineage development of adult human mesenchymal stem cells in high-density culture. Differentiation. 2003; 71: 567-77.

54. Sekiya I, Larson BL, Vuoristo JT, Reger RL, Prockop DJ. Comparison of effect of BMP-2, -4 , and -6 on in vitro cartilage formation of human adult stem cells from bone marrow stroma. Cell Tissue Res. 2005; 320: 269-76.

55. Murphy MK, Huey DJ, Hu JC, Athanasiou KA. TGF-beta1, GDF-5, and BMP-2 stimulation induces chondrogenesis in expanded human articular chondrocytes and marrow-derived stromal cells. Stem Cells. 2015; 33: 762-73.

56. Mehta M, Schmidt-Bleek K, Duda GN, Mooney DJ. Biomaterial delivery of morphogens to mimic the natural healing cascade in bone. Adv Drug Deliv Rev. 2012; 64: 1257-76. 